\title{
Local Structure of CPO-27-Ni Metallorganic Framework upon Dehydration and Coordination of NO
}

\author{
Francesca Bonino ${ }^{\dagger}$ Sachin Chavan,${ }^{\dagger}$ Jenny G. Vitillo, ${ }^{\dagger}$ Elena Groppo ${ }^{\dagger}$ Giovanni Agostini ${ }^{\dagger}$ \\ Carlo Lamberti, ${ }^{\dagger}$ Pascal D. C. Dietzel, ${ }^{\ddagger}$ Carmelo Prestipino,${ }^{\S}$ and Silvia Bordiga* ${ }^{*} \dagger$ \\ Department of Inorganic, Physical and Materials Chemistry and NIS Centre of Excellence, Università di \\ Torino, Via P. Giuria 7, 10125 Torino, Italy, INSTM Centro di Riferimento, Department of Hydrocarbon \\ Process Chemistry, SINTEF Materials and Chemistry, P.O. Box 124, Blindern, 031 Oslo, Norway, Centre \\ for Materials Science and Nanotechnology, Department of Chemistry, University of Oslo, \\ Postboks 1033, Blindern N-0315, Oslo, Norway, and ESRF, 6 rue Jules Horowitz, BP220, F-38043, \\ Grenoble CEDEX, France
}

Received March 9, 2008. Revised Manuscript Received April 20, 2008

\begin{abstract}
Coordination polymer $\mathrm{Ni}_{2}(\mathrm{dhtp})\left(\mathrm{H}_{2} \mathrm{O}\right)_{2} \cdot 8 \mathrm{H}_{2} \mathrm{O}$ is a $3 \mathrm{D}$ network that maintains crystallinity and porosity after solvent removal. A mild thermal treatment in high vacuo at $393 \mathrm{~K}$ removes not only water physisorbed on the walls of the structure but also water directly coordinated to the Ni(II) sites. This procedure allows us to obtain a MOF material with honeycomb structure able to strongly coordinate NO. In this contribution the characterization of CPO-27-Ni in respect to structural (EXAFS compared to XRD), vibrational (IR and Raman) and electronic (UV, XANES, and luminescence) properties is described in the case of the as prepared sample, of the dehydrated sample and after NO interaction. NO is strongly bonded at the $\mathrm{Ni}$ (II) sites, forming a 1:1 adduct; its presence causes large modification of the vibrational and electronic properties of the material with respect to the dehydrated one. Quantitative data considering energetic aspects (microcalorimetric measurements) are also included. The ability of $\mathrm{H}_{2} \mathrm{O}$ molecules to slowly displace $\mathrm{NO}$ from the $\mathrm{Ni}(\mathrm{II})$ sites makes this material a promising candidate for NO delivery inside biological tissues.
\end{abstract}

\section{Introduction}

Metallorganic frameworks (MOFs, also known as "coordination polymers") are crystalline nanoporous materials comprised of metal containing clusters connected threedimensionally by polyfunctional organic ligands. The ligands act as spacers, creating an open porous three-dimensional structure, with very high pore volume and surface area. This hybrid architecture opens the possibility to design and synthesize a great variety of new porous materials, which are in principle able to display novel functionalities that are potentially exploitable for a number of applications in catalysis, ion-exchange, nonlinear optics, as sensors, in gas separation, and/or storage. ${ }^{1-14}$ In this respect, possessing very low density accompanied by large surface area and accessible volume, they have been considered as very promising materials for dihydrogen molecular adsorption. ${ }^{15-18}$

\footnotetext{
* Corresponding author. E-mail: silvia.bordiga@ unito.it. Tel.: 39011670 7140 Fax: 300116707855

† Università di Torino.

* SINTEF Materials and Chemistry.

$\S$ ESRF.

(1) Ferey, G. Chem. Mater. 2001, 13, 3084-3098.

(2) Stein, A. Adv. Mater. 2003, 15, 763-775.

(3) Stein, A.; Melde, B. J.; Schroden, R. C. Adv. Mater. 2000, 12, 14031419.

(4) Yaghi, O. M.; Davis, C. E.; Li, G. M.; Li, H. L. J. Am. Chem. Soc. 1997, 119, 2861-2868.

(5) Yaghi, O. M.; Jernigan, R.; Li, H. L.; Davis, C. E.; Groy, T. L. J. Chem. Soc., Dalton Trans. 1997, 2383-2384.

(6) James, S. L. Chem. Soc. Rev. 2003, 32, 276-288.

(7) Janiak, C. Dalton Trans. 2003, 2781-2804.

(8) Kitagawa, S.; Kitaura, R.; Noro, S. Angew. Chem., Int. Ed. 2004, 43,
} 2334-2375.
Inspired by these promising properties, Dietzel et al. ${ }^{19}$ synthesized a three-dimensional honeycomb-like metallorganic framework with $\mathrm{Ni}(\mathrm{II})$ as the metal component: $\mathrm{Ni}_{2}($ dhtp $)\left(\mathrm{H}_{2} \mathrm{O}\right)_{2} \cdot 8 \mathrm{H}_{2} \mathrm{O}($ dhtp $=2,5$-dihydroxyterephthalic acid). Only few Ni-based coordination polymers with a high specific surface area have been investigated up to now, which are isostructural to framework materials with zinc and cobalt as metal component. ${ }^{20-27}$ This new

(9) Schüth, F.; Sing, K. S. W.; Weitkamp, J., Handbook of Porous Solids; Wiley-VCH: Weinheim, Germany, 2002; Vol. 2.

(10) Bordiga, S.; Lamberti, C.; Ricchiardi, G.; Regli, L.; Bonino, F.; Damin, A.; Lillerud, K. P.; Bjorgen, M.; Zecchina, A. Chem. Commun. 2004, 2300-2301.

(11) Bordiga, S.; Vitillo, J. G.; Ricchiardi, G.; Regli, L.; Cocina, D.; Zecchina, A.; Arstad, B.; Bjorgen, M.; Hafizovic, J.; Lillerud, K. P. J. Phys. Chem. B 2005, 109, 18237-18242.

(12) Szeto, K. C.; Lillerud, K. P.; Tilset, M.; Bjorgen, M.; Prestipino, C.; Zecchina, A.; Lamberti, C.; Bordiga, S. J. Phys. Chem. B 2006, 110, 21509-21520.

(13) Szeto, K. C.; Prestipino, C.; Lamberti, C.; Zecchina, A.; Bordiga, S.; Bjorgen, M.; Tilset, M.; Lillerud, K. P. Chem. Mater. 2007, 19, 211220.

(14) Hafizovic, J.; Bjorgen, M.; Olsbye, U.; Dietzel, P. D. C.; Bordiga, S.; Prestipino, C.; Lamberti, C.; Lillerud, K. P. J. Am. Chem. Soc. 2007, $129,3612-3620$.

(15) Latroche, M.; Surble, S.; Serre, C.; Mellot-Draznieks, C.; Llewellyn, P. L.; Lee, J. H.; Chang, J. S.; Jhung, S. H.; Ferey, G. Angew. Chem., Int. Ed. 2006, 45, 8227-8231.

(16) Wong-Foy, A. G.; Matzger, A. J.; Yaghi, O. M. J. Am. Chem. Soc. 2006, 128, 3494-3495.

(17) Dinca, M.; Dailly, A.; Liu, Y.; Brown, C. M.; Neumann, D. A.; Long, J. R. J. Am. Chem. Soc. 2006, 128, 16876-16883.

(18) Chen, B. L.; Ockwig, N. W.; Millward, A. R.; Contreras, D. S.; Yaghi, O. M. Angew. Chem., Int. Ed. 2005, 44, 4745-4749.

(19) Dietzel, P. D. C.; Panella, B.; Hirscher, M.; Blom, R.; Fjellvag, H. Chem. Commun. 2006, 959-961. 

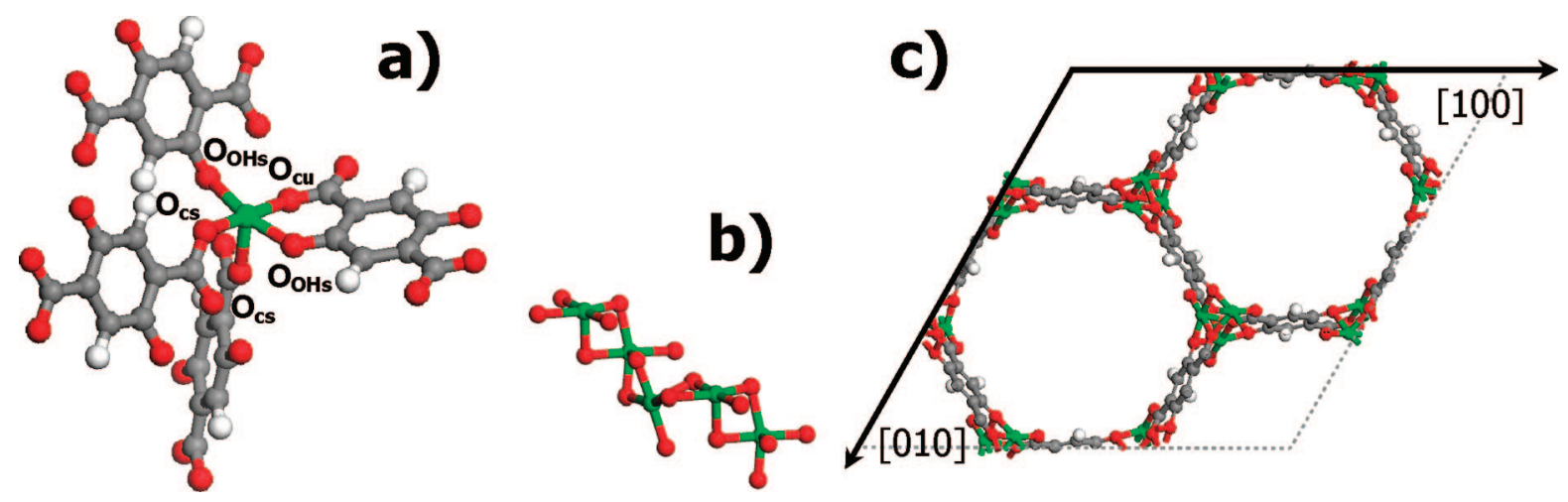

Figure 1. Pictorial representation at different magnification grades of a dehydrated CPO-27-Ni sample. (a) Coordination sphere of Ni(II) (see the text for O labels). (b) Inorganic nodes involving $\mathrm{Ni}(\mathrm{II})$. (c) Bidimensional view of the honeycomb structure. The $\mathrm{C}$ atoms are reported in gray, $\mathrm{H}$ atoms in white, $\mathrm{O}$ in red, and $\mathrm{Ni}$ in green.

material, called CPO-27-Ni, contains one-dimensional channels, which are filled with water that can be removed by a mild thermal treatment. Upon dehydration the crystalline structure is preserved and a material with a high surface area containing unsaturated metal sites organized in helicoidal chains is obtained. Figure 1 reports different magnification grades of dehydrated CPO-27-Ni structure: (a) reports the coordination sphere of $\mathrm{Ni}$ (II); (b) illustrates the inorganic nodes involving $\mathrm{Ni}(\mathrm{II})$; (c) shows a bidimensional view of the honeycomb structure (unit cell). All the oxygen atoms of the ligands are involved in the coordination of nickel atoms. This accounts for five of the oxygen atoms coordinating each nickel atom, whereas the sixth coordinative bond is normally occupied by a water molecule that points toward the cavity. Because of the helical arrangement of the $\mathrm{NiO}_{5}$ units, the nearest $\mathrm{Ni}$ atoms are exposed in different channels: for this reason the smallest distance between nearest $\mathrm{Ni}$ ions exposed in the same channel is of $6.8 \AA$. All the $\mathrm{Ni}$ (II) ions are identical with respect to the first coordination sphere, showing five oxygens that slightly differ one from the other (Figure 1a). In particular, there are two $\mathrm{O}_{\mathrm{cs}}$ (oxygens from two different carboxylate units, each of them shared with another $\mathrm{Ni}$ ion), one $\mathrm{O}_{\mathrm{cu}}$ (oxygen from one of the previous carboxylate units, not shared with another $\mathrm{Ni}$ ion), and two $\mathrm{O}_{\mathrm{OHs}}$ (oxygens from the deprotonated $\mathrm{OH}$ group of two other linkers, each of them shared with another Ni ion). It has been shown from ab initio calculations that among all the oxygens, $\mathrm{O}_{\mathrm{cu}}$ is the most negative, followed by $\mathrm{O}_{\mathrm{OHs}}$, while the other two oxygens $\left(\mathrm{O}_{\mathrm{cs}}\right)$ are much less electronegative. ${ }^{28}$ Incoming molecules would experience a positive electrostatic potential along the CPO-27-Ni channels with the exception

(20) Rosi, N. L.; Kim, J.; Eddaoudi, M.; Chen, B. L.; O'Keeffe, M.; Yaghi, O. M. J. Am. Chem. Soc. 2005, 127, 1504-1518.

(21) Dietzel, P. D. C.; Morita, Y.; Blom, R.; Fjellvag, H. Angew. Chem., Int. Ed. 2005, 44, 6354-6358.

(22) Dietzel, P. D. C.; Johnsen, R. E.; Blom, R.; Fjellvåg, H. Chem.-Eur. J. 2008, 14, 2389-2397.

(23) Kaye, S. S.; Long, J. R. J. Am. Chem. Soc. 2005, 127, 6506-6507.

(24) Lee, E. Y.; Suh, M. P. Angew. Chem., Int. Ed. 2004, 43, 2798-2801.

(25) Zhao, X. B.; Xiao, B.; Fletcher, A. J.; Thomas, K. M.; Bradshaw, D.; Rosseinsky, M. J. Science 2004, 306, 1012-1015.

(26) Dinca, M.; Long, J. R. J. Am. Chem. Soc. 2007, 129, 11172-11176.

(27) Forster, P. M.; Eckert, J.; Heiken, B. D.; Parise, J. B.; Yoon, J. W.; Jhung, S. H.; Chang, J. S.; Cheetham, A. K. J. Am. Chem. Soc. 2006, $128,16846-16850$. of the $\mathrm{O}_{\mathrm{OHs}}$ and the $\mathrm{O}_{\mathrm{cu}}$ vicinities (see Figure $\mathrm{S} 1$ in the Supporting Information).

At the moment, this material has been tested in respect of hydrogen storage capacity finding a result not exciting in term of amount of hydrogen stored $(1.8 \mathrm{wt} \%$ at $77 \mathrm{~K}$ and 45 bar $^{19}$ as compared with other microporous materials having a higher surface area ${ }^{15-17}$ but very interesting in terms of interaction energy $(13.5 \mathrm{~kJ} / \mathrm{mol}){ }^{28}$ This value is very close to the value of $15.1 \mathrm{~kJ} / \mathrm{mol}$ predicted by Bhatia and Myers, ${ }^{29}$ ?xpp foot;3829ref29;10?>,${ }^{30}$ to be the optimum adsorption enthalpy for ambient temperature storage of hydrogen and delivery between 30 and 1.5 bar pressure. The nice reactivity toward hydrogen encouraged us to explore the adsorption properties of this material toward other molecules and pushed the research to better understand the properties of this material in both hydrated and dehydrated forms. It is known from XRD data that upon dehydration, the first coordination sphere of $\mathrm{Ni}(\mathrm{II})$ changes. Likely, significant modifications of geometric parameters related to the $\mathrm{Ni}$ (II) sites imply some fundamental rearrangements that merit a specific investigation through the combined use of different spectroscopies. The present work is devoted to the description of the effect of dehydration on CPO-27-Ni in terms of structural (EXAFS to be compared with XRD results), vibrational (IR and Raman), and electronic (UV-vis, fluorescence and XANES) modifications and its response upon nitric oxide (NO) interaction. High NO adsorption is of great interest for environmental applications in gas separation and in NOx traps for lean burn engines. NO is also an extremely important molecule in biology, and NOstoring solids have potential applications as antithrombosis materials. ${ }^{31-33}$ Moreover, NO plays also an important role in the cutaneous response to UV radiation and in cutaneous

(28) Vitillo, J. G.; Regli, L.; Chavan, S.; Ricchiardi, G.; Spoto, G.; Dietzel, P. D. C.; Bordiga, S.; Zecchina, A J. Am. Chem. Soc. 2008, 130, DOI: $10.1021 / \mathrm{ja} 0007159$.

(29) Bhatia, S. K.; Myers, A. L. Langmuir 2006, 22, 1688-1700.

(30) Gigras, A.; Bhatia, S. K.; Kumar, A. V. A.; Myers, A. L. Carbon 2007, 45, 1043-1050.

(31) Wheatley, P. S.; Butler, A. R.; Crane, M. S.; Fox, S.; Xiao, B.; Rossi, A. G.; Megson, I. L.; Morris, R. E. J. Am. Chem. Soc. 2006, 128, 502-509.

(32) Xiao, B.; Wheatley, P. S.; Zhao, X. B.; Fletcher, A. J.; Fox, S.; Rossi, A. G.; Megson, I. L.; Bordiga, S.; Regli, L.; Thomas, K. M.; Morris, R. E. J. Am. Chem. Soc. 2007, 129, 1203-1209.

(33) McKinlay, A. C.; Xiao, B.; Wragg, D. S.; Wheatley, P. S.; Megson, I. L.; Morris, R. E. J. Am. Chem. Soc. 2008, 130, accepted. 
inflammation, ${ }^{34}$ and is associated with diminished antioxidative capacity in skin cells, hindered wound healing, unbalanced inflammatory reactions, and disturbed immunological responses. ${ }^{35}$ Use of topically applied NO donors might represent an auspicious new therapeutic approach in the field of dermatology. Consequently, the delivery of exogenous NO is an attractive therapy for many ailments, but it requires the development of materials that can store significant quantities of $\mathrm{NO}$ and then deliver it to specific sites in the body.

\section{Experimental Section}

The CPO-27-Ni material was prepared from a nickel(II) acetate and 2,5-dihydroxyterephthalic acid reaction in a $\mathrm{THF}$-water mixture to yield an ochre substance, $\mathrm{Ni}_{2}(\mathrm{dhtp})\left(\mathrm{H}_{2} \mathrm{O}\right)_{2} \cdot 8 \quad \mathrm{H}_{2} \mathrm{O}$, following a recipe reported in the literature ${ }^{19} \mathrm{X}$-ray powder data showed the high crystallinity of the sample for which a BET of $1200 \mathrm{~m}^{2} \mathrm{~g}^{-1}$ was evaluated (Langmuir surface area of $1315 \mathrm{~m}^{2}$ $\mathrm{g}^{-1}$ ). The sample was not much sensible to moisture, maintaining its high crystallinity and porosity. To induce dehydration, CPO$27-\mathrm{Ni}$ samples were pretreated under high vacuum at $393 \mathrm{~K}$ for $1 \mathrm{~h}$. All the spectroscopic measurements were performed in controlled atmosphere by using ad hoc cells that allow thermal treatment in high vacuo, dosages, and in situ spectra collection. NO gas was carefully purified by distillation in order to remove other undesired nitrogen oxides and it was dosed, by means of a vacuum line, on the samples at RT.

Parallel measurements were performed on powdered samples in case of DR-UV-vis-NIR (Cary 5 spectrophotometer, equipped with a reflectance sphere) and Fluorescence (Fluorolog-3, HORIBA JOBIN YVON spectrofluorometer, equipped with a $450 \mathrm{~W}$ xenon lamp as an excitation source) spectroscopies.

FTIR spectra were collected in transmission mode on selfsupporting wafer or on a thin film on a silicon wafer, in controlled atmosphere. The spectra were recorded at $2 \mathrm{~cm}^{-1}$ resolution on a Bruker IFS 66 FTIR spectrometer, equipped with a MCT detector. Raman spectra were recorded by using a Renishaw Raman Microscope spectrometer. $\mathrm{An}{ }^{+}$laser emitting at $514 \mathrm{~nm}$ was used, in which the output power was limited to $1 \%(100 \%$ power $=8.2 \mathrm{~mW}$ at the sample $)$ in order to avoid sample damage. The photons scattered by the sample were dispersed by a 1800 lines/mm grating monochromator and simultaneously collected on a CCD camera; the collection optic was set at $20 \mathrm{X}$ objective. The spectra were obtained by collecting 10 acquisitions (each of $10 \mathrm{~s}$ ) on a self-supporting wafer put in a homemade cell with a suprasil quartz cuvette that allowed measurements in a controlled atmosphere.

Volumetric and calorimetric isotherms of NO adsorption at 303 $\mathrm{K}$ were carried out in a microcalorimeter (Tian-Calvet type by Setaram, France) equipped with a calibrated glass gas-volumetric apparatus, which enabled us to simultaneously determine the adsorbed amounts and the heat evolved at increasing equilibrium pressure for small increments of the adsorptive. ${ }^{36}$ The absolute pressures were measured by means of a transducer gauge (Barocell, Edwards, 0-100 mbar).

$\mathrm{X}$-ray absorption experiments on $\mathrm{Ni} \mathrm{K}$-edge were performed at the $\mathrm{BM} 29^{37}$ beamline at the European Synchrotron Radiation

(34) Mowbray, M.; Tan, X. J.; Wheatley, P. S.; Morris, R. E.; Weller, R. B. J. Invest. Dermatol. 2008, 128, 352-360.

(35) Kroncke, K. D.; Suschek, C. V. J. Invest. Dermatol. 2008, 128, 258260.

(36) Bolis, V.; Cerrato, G.; Magnacca, G.; Morterra, C. Thermochim. Acta 1998, 312, 63-77.
Facility (ESRF). The monochromator was equipped with two $\mathrm{Si}(111)$ flat crystals and harmonic rejection was achieved using Rhcoated mirrors after monochromator. The following experimental geometry was adopted: (1) $I_{0}$ (10\% efficiency); (2) MOF sample; (3) $I_{1}$ (50\% efficiency); (4) reference Ni foil; (5) $I_{2}$ (80\% efficiency). This setup allows a direct energy/angle calibration for each spectrum avoiding any problem related to little energy shifts due to small thermal instability of the monochromator crystals. ${ }^{38}$ For the XANES part, a sampling step of $0.3 \mathrm{eV}$ has been applied, whereas for the EXAFS part, a sampling step of $0.025 \AA^{-1}$ has been considered with an integration time of $3 \mathrm{~s}$ /point. Samples, in form of selfsupported pellets of optimized thickness, have been located inside an ad hoc conceived cell developed at ESRF (by Prestipino, Steinman, and Pasternack) that allows, evacuation, gas dosage and temperature variation in the $100-800 \mathrm{~K}$ range. This experimental setup guarantees the same degrees of freedom of the cell described in ref 39 .

The extraction of the $\chi(k)$ function has been performed using Klementev's programs. ${ }^{40}$ For each sample, four consecutive EXAFS spectra have been collected and corresponding $\chi(k)$ functions have been averaged before data analysis. EXAFS data analysis has been performed using the Arthemis software. ${ }^{41}$ Phases and amplitudes have been calculated by FEFF6 code $^{42}$ using as input the structure solved by powder X-ray diffraction. ${ }^{19}$ Phases and amplitudes have been successfully checked with $\mathrm{NiO}$ model compound. ${ }^{43,44}$ For each sample, the averaged $k^{3} \chi(k)$ function were Fourier Transformed in the $\Delta k=2.00-18.00 \AA^{-1}$ interval. The fits were performed in R-space in the $\Delta R=1.00-5.00 \AA$ range $(2 \Delta k \Delta R / \pi>40)$.

\section{Effect of Dehydration on CPO-27-Ni: Spectroscopic Studies}

One of the most crucial points for MOFs is their behavior upon removal of the solvent. Only sufficiently robust coordination polymer frameworks that remain stable and show permanent porosity upon solvent removal can find application in gas storage and separation. For this reason, a big effort has been devoted to characterize these materials with respect to their changes upon solvent removal. Most of the studies refer just to structural determination performed with diffraction methods. ${ }^{45,46}$ In some cases, ${ }^{19,22}$ materials with similar topology showed different behaviors, that might be fully understood only by coupling the structural data with

(37) Filipponi, A.; Borowski, M.; Bowron, D. T.; Ansell, S.; Di Cicco, A.; De Panfilis, S.; Itie, J. P. Rev. Sci. Instrum. 2000, 71, 2422-2432.

(38) Lamberti, C.; Bordiga, S.; Bonino, F.; Prestipino, C.; Berlier, G.; Capello, L.; D’Acapito, F.; Xamena, F. X. L. I.; Zecchina, A. Phys. Chem. Chem. Phys. 2003, 5, 4502-4509.

(39) Lamberti, C.; Prestipino, C.; Bordiga, S.; Berlier, G.; Spoto, G.; Zecchina, A.; Laloni, A.; La Manna, F.; D'Anca, F.; Felici, R.; D’Acapito, F.; Roy, P. Nucl. Instrum. Methods Phys. Res., Sect. B 2003, 200, 196-201.

(40) Klementev, K. V. Nucl. Instrum. Methods Phys. Res., Sect. A 2000, 448, 299-301.

(41) Ravel, B.; Newville, M. J. Synchrotron Radiat. 2005, 12, 537-541.

(42) Ankudinov, A. L.; Ravel, B.; Rehr, J. J.; Conradson, S. D. Phys. Rev. B. 1998, 58, 7565-7576.

(43) Lamberti, C.; Groppo, E.; Prestipino, C.; Casassa, S.; Ferrari, A. M.; Pisani, C.; Giovanardi, C.; Luches, P.; Valeri, S.; Boscherini, F. Phys. Rev. Lett. 2003, 91, 046101.

(44) Groppo, E.; Prestipino, C.; Lamberti, C.; Luches, P.; Giovanardi, C.; Boscherini, F. J. Phys. Chem. B 2003, 107, 4597-4606.

(45) Serre, C.; Mellot-Draznieks, C.; Surble, S.; Audebrand, N.; Filinchuk, Y.; Ferey, G. Science 2007, 315, 1828-1831.

(46) Serre, C.; Millange, F.; Thouvenot, C.; Nogues, M.; Marsolier, G.; Louer, D.; Ferey, G. J. Am. Chem. Soc. 2002, 124, 13519-13526. 


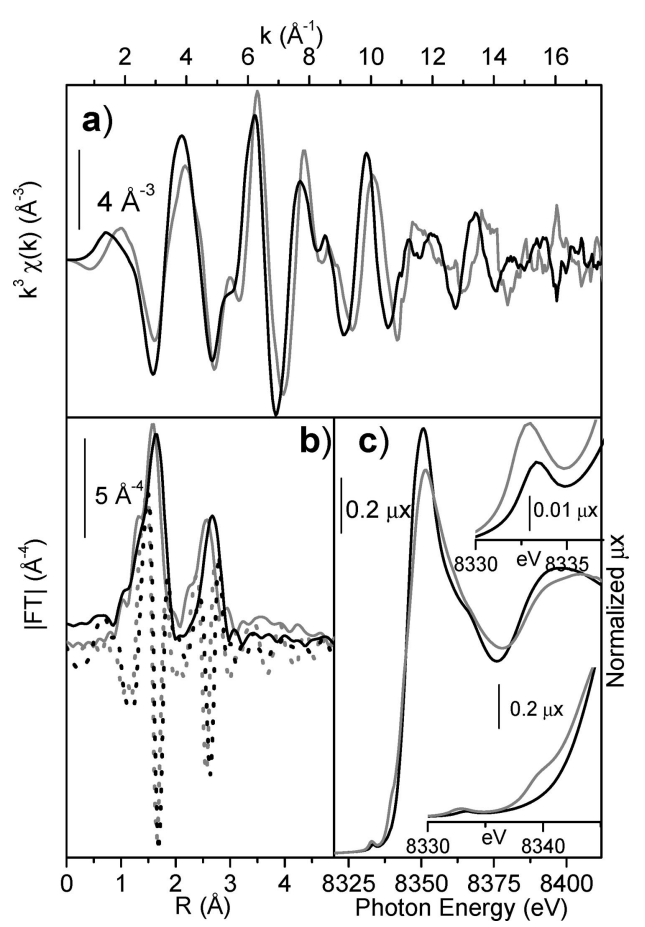

Figure 2. Comparison between hydrated (black curves) and dehydrated (gray curves) CPO-27-Ni observed from X-ray absorption spectroscopies. (a) $k^{3}$ weighted $\chi(k)$. (b) Corresponding FT in their modulus (full lines) and imaginary part (dotted lines). (c) Normalized XANES. Insets report a zoom on the dipole forbidden $1 \mathrm{~s} \rightarrow 3 \mathrm{~d}$ (top) and on the dipole allowed $1 \mathrm{~s} \rightarrow 4 \mathrm{p}$ (bottom) electronic transitions.

spectroscopic investigation as already reported in few cases. ${ }^{10-14,47,48}$

3.1. Structural Modifications: EXAFS Data. The effect of water removal from CPO-27-Ni significantly affects the X-ray absorption spectra of the material, in both its XANES (vide infra section 3.2) and EXAFS region, as appreciable from Figure 2. In particular, the $k^{3}$-weighted $\chi(k)$ signal (Figure 2a) exhibits a frequency decrease (period increase) in $k$-space, reflecting a shortening of the average $\mathrm{Ni}-\mathrm{O}$ bond length, according to XRD refinements. ${ }^{19}$ The main beats at 5.6 and $8.3 \AA^{-1}$ are slightly perturbed by the dehydration process, that reflects a slight framework rearrangement maintaining an ordered higher shells signal. The shortening of the average first $\mathrm{Ni}-\mathrm{O}$ shell is directly visible in $R$-space (Figure $2 \mathrm{~b}$ ), where the phase-uncorrected Fourier Transform (FT) of the $k^{3} \chi(k)$ shown in part (a) exhibits a first shell peak, due to the first $\mathrm{Ni}-\mathrm{O}$ shells contributions (see Figure 3, red curves), that moves from 1.64 to $1.58 \AA(\Delta R \approx-0.06 \AA)$. Even more evident is the shortening of the second shell peak, from 2.68 to $2.56 \AA$ $(\Delta R \approx-0.08 \AA$ ). This second shell signal is mainly dominated by the first $\mathrm{Ni}-\mathrm{Ni}$ distance (vide infra, Figure 3, blue curve) that, according to XRD refinement, ${ }^{19}$ moves from 2.979 down to $2.904 \AA(\Delta R=-0.075 \AA)$. A similar behavior upon dehydration has been observed for the HKUST-1 system, a CuMOF. ${ }^{48}$ The signal at higher $R(3.0 \AA<R<5.5 \AA)$ undergoes an important increase in intensity upon dehydration, reflecting

(47) Bordiga, S.; Regli, L.; Bonino, F.; Groppo, E.; Lamberti, C.; Xiao, B.; Wheatley, P. S.; Morris, R. E.; A., Z Phys. Chem. Chem. Phys. 2007, 9, 2676.

(48) Prestipino, C.; Regli, L.; Vitillo, J. G.; Bonino, F.; Damin, A.; Lamberti, C.; Zecchina, A.; Solari, P. L.; Kongshaug, K. O.; Bordiga, S. Chem. Mater. 2006, 18, 1337-1346.

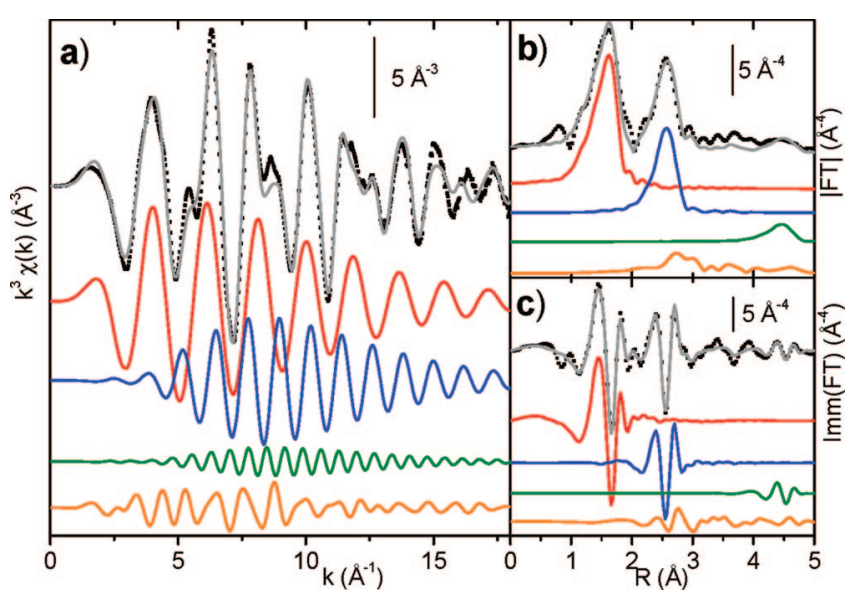

Figure 3. Summary of results obtained from the EXAFS data analysis performed on the dehydrated sample measured at low temperature (a) in $k$-space, and in R-space, both (b) modulus and (c) imaginary part. Each part reports from top to bottom: the experimental data (black scattered squares) superimposed to the best fit (gray curve); the 5-degenerate SS contribution of the oxygen (red); the SS contribution of the first Ni neighbor (blue); the SS contribution of the second Ni neighbor (green); the sum of all other SS and MS contributions included in the fit (orange). Values of the optimized parameters are reported in the second column of Table 1.

either an increase of order in the short-range scale around $\mathrm{Ni}$ or a rearrangement of the high $R$ scattering paths in a more constructive way, or both.

3.1.1. EXAFS Analysis of the Dehydrated Material. The dehydrated case has been chosen as starting data set for the EXAFS analysis. The presence of adsorbed molecules, in fact, represents an increasing degree of complexity. Notwithstanding the knowledge of the structure from XRD refinement, the data analysis was not straightforward because an important number of different single and multiple scattering (SS and MS) paths contribute significantly to the overall signal. By arbitrarily defining as 100 the amplitude of the stronger signal (corresponding to the first neighbor O), the FEFF code computed 52 paths having a relative intensity higher than 20 .

XRD refinement resulted in five different $\mathrm{Ni}-\mathrm{O}$ first shell distances at $1.885,1.945,1.991,2.074$, and $2.120 \AA$. It was, however, impossible to fit separately these five contributions, because the presence of 5 signals with almost the same amplitude (100, 93, 89, 81, and 77) and slightly different distances resulted in fit instabilities. For this reason, a fit with only one oxygen shell at an average starting distance (with a degeneration factor of 5) has been chosen (vide infra, Figure 3 , red curve). This accounts very well for the first shell peak in the $0.85-2.10 \AA$ A region (phase uncorrected distances in Figure $2 \mathrm{~b})$. Coming to the higher $R$ range, the second shell peak (2.10-3.10 $\AA$ region in Figure $2 b)$ is mainly due to the contribution of the $\mathrm{Ni}-\mathrm{Ni}$ signal (amplitude 78, degeneration 2 ), vide infra Figure 3, blue curve. Unfortunately, the presence of 10 additional significant paths (both SS paths of the $\mathrm{C}$ atoms of the carboxylate units and MS triangular paths involving $\mathrm{O}$ and $\mathrm{C}$ atoms) with intensities ranging from 29 to 85 prevents to completely fit the $2.10-3.10 \AA$ region with the unique $\mathrm{Ni}-\mathrm{Ni}$ contribution. In the 3.10-4.20 Å region, an impressive number of different paths contributes to the experimental signal. Finally, the 4.2-5.0 A region is dominated by the second Ni neighbor (intensity 41, degeneration 2), vide infra Figure 3, green curve. 
Table 1. Summary of the Parameters Optimized by Fitting the EXAFS Data Collected at Temperature $T^{a}$

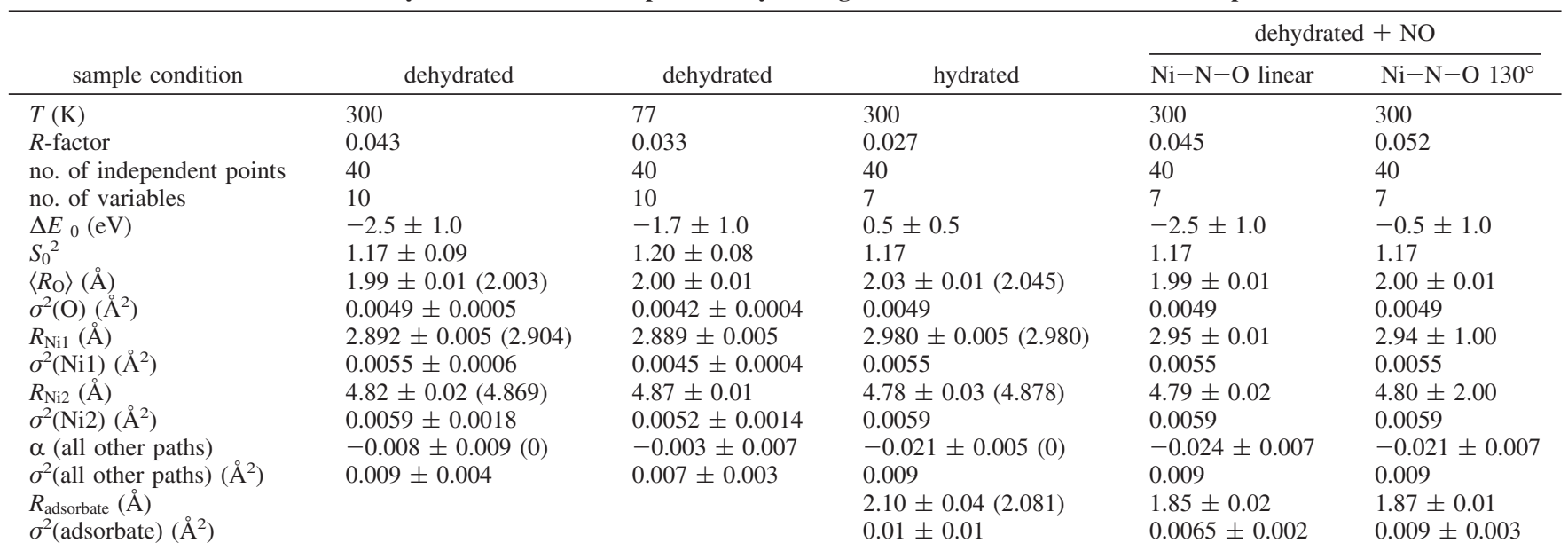

${ }^{a}$ The fits were performed in $R$-space in the $1.0-5.0 \AA$ range over $k^{3}$-weighted FT of the $\chi(k)$ functions performed in the $2.0-18.0 \AA^{-1}$ interval. A single $\Delta E_{0}$ and a single $S_{0}{ }^{2}$ have been optimized for all $\mathrm{SS}$ and MS paths. The $\mathrm{Ni}-\mathrm{O}$ and $\mathrm{Ni}-\mathrm{Ni}$ (first and second neighbor) $\mathrm{SS}$ paths have been modeled with their own path length and Debye-Waller factors, whereas a unique $\sigma^{2}$ and unique path length parameter $\alpha$, common to all other SS and MS paths, have been optimized. Non optimized parameters are recognizable by the absence of corresponding error bars. When possible, comparison with the values obtained from powder $\mathrm{XRD}^{19}$ are reported in parentheses.

On the basis of these considerations, we performed the fit in $R$-space including all SS and MS paths with intensity higher than 10 with an effective path length shorter than $5.00 \AA$, optimizing the following 10 independent parameters: an unique amplitude factor $\left(S_{0}{ }^{2}\right)$ and an unique energy shift $\left(\Delta E_{0}\right)$ for all paths; the distances $\left(\left\langle R_{\mathrm{O}}\right\rangle, R_{\mathrm{Ni} 1}\right.$, and $\left.R_{\mathrm{Ni} 2}\right)$ and the Debye-Waller factor $\left[\sigma^{2}(\mathrm{O}), \sigma^{2}(\mathrm{Ni} 1)\right.$, and $\left.\sigma^{2}(\mathrm{Ni} 2)\right]$ for the $\mathrm{SS} \mathrm{Ni}-\mathrm{O}, \mathrm{Ni}-\mathrm{Ni}$, and $\mathrm{Ni}-\mathrm{Ni}$ paths around 2.0, 2.9, and $4.7 \AA$, respectively; and for all remaining paths an unique Debye-Waller factor $\left(\sigma^{2}\right)$ and distance enlargement factor $(\alpha)$, parametrizing the path length variation as $\Delta \mathrm{R}=\alpha$ Reff. $^{49}$ This fit resulted in an excellent agreement with the experimental results $(R$-factor $=$ 0.043 ) showing physically meaningful values for the optimized parameters $S_{0}^{2}, \Delta E_{0}$, and Debye-Waller factors (see first column in Table 1). As for the optimized distances, they are in good agreement with those obtained from XRD: ${ }^{19}$ the average oxygen distance, $\left\langle\mathrm{R}_{\mathrm{O}}\right\rangle=1.99 \pm 0.01 \AA$, match the XRD average (2.003 $\AA$ ), within one esd (estimated standard deviation); the first $\left(R_{\mathrm{Ni} 1}=2.892 \pm 0.005 \AA\right)$ and the second $\left(R_{\mathrm{Ni} 2}\right.$ $=4.82 \pm 0.02 \AA), \mathrm{Ni}-\mathrm{Ni}$ distances within two esd. Concerning all remaining scattering paths, the EXAFS best fit suggests a lattice contraction of $0.8 \%$, a value that is within the standard incertitude of EXAFS technique. The validity of the fit is testified by the fact that only two couples of fitted parameters have significant correlations factors $\left(\mathrm{S}_{0}{ }^{2} / \sigma^{2}(\mathrm{O})=0.80 ; \Delta E_{0} /\right.$ $\left\langle R_{\mathrm{O}}\right\rangle=0.78$ ), whereas all the remaining couples show correlation parameters below 0.5 in absolute value.

To further check whether the obtained fit is the correct one or is just a mathematical one, we applied the same approach to the sample measured at liquid nitrogen temperature. The results are reported in the second column of Table 1. The $S_{0}^{2}$ and $\Delta E_{0}$ parameters do not change within experimental errors, while all Debye-Waller factors decreased as expected. The further improvement of the experimental data due to temperature lowering results in a

(49) Reff is defined as one half of the path length. For SS paths, Reff coincides consequently with the distance between the absorbing $\mathrm{Ni}$ and the scattering atom. further decrease of all correlations among fitted variables. The validity of the fit results is thus confirmed.

Figure 3 reports in both $k$ - (a) and $R$-spaces (b and c) the fit obtained on the dehydrated sample measured at low temperature, together with the different contributions to the overall best fit signal. In $k$-space (Figure $3 a$ ), the quality of the fit is excellent until $15 \AA^{-1}$, whereas in the $15-18 \AA^{-1}$ $k$-interval, the amplitude of the EXAFS oscillations are only partially reproduced by the model. A similar fit performed on the reduced $2-15 \AA^{-1} k$-interval resulted, within experimental errors, in equivalent values for the optimized parameters (data not reported for brevity). In $R$-space (Figure 3 bc) the agreement is excellent in the regions $1.0-3.2$ and 4.1-5.0 А. The less accuracy of the fit in the 3.2-4.1 region is due to the fact that the experimental signal contains contribution from a very high number of paths, none of them being dominating, that have been optimized using only two parameters $\left(\sigma^{2}\right.$ and $\alpha$ ), being the $\Delta E_{0}$ and the $S_{0}{ }^{2}$ parameters sheared with all other paths.

3.1.2. EXAFS Analysis of the Hydrated Material. Also for the hydrated material, the structure determined from powder XRD has been used as starting model ${ }^{19}$ for the amplitude and phase calculation of all scattering paths and for the starting values of the fits. In this case, the addition of a further $\mathrm{Ni}-\mathrm{O}$ scattering path in the first shell peak results in even more severe correlation problems among fitted parameters. Any attempt to add two further fitting parameters $\mathrm{Ni}-\mathrm{O}_{\text {water }}$ distance ( $\left.R_{\text {adsorbate }}\right)$ and corresponding Debye - Waller factor $\left(\sigma^{2}\right.$ (adsorbate) $)$, results in non physical values of the optimized parameters and in huge associated errors. For this reason, the fit of the dehydrated material has been used to fix as much parameters as possible. It has been assumed that water adsorption/desorption does not affect appreciably the amplitude factor $S_{0}{ }^{2}$, as well as all framework Debye-Waller factors $\sigma^{2}(\mathrm{O}), \sigma^{2}(\mathrm{Ni} 1), \sigma^{2}(\mathrm{Ni} 2)$, and $\sigma^{2}$. Under those assumptions, a seven-parameter fit was run, see third column in Table 1. In the fit, the main correlations concern: $\left\langle\mathrm{R}_{\mathrm{O}}\right\rangle / \sigma^{2}$ (adsorbate) $=0.93 ; R_{\text {adsorbate }} / \sigma^{2}$ (adsorbate $)=$ $-0.76 ;\left\langle\mathrm{R}_{\mathrm{O}}\right\rangle / R_{\text {adsorbate }}=-0.71 ; \alpha / R_{\mathrm{Ni} 2}=0.66$, all the remaining 


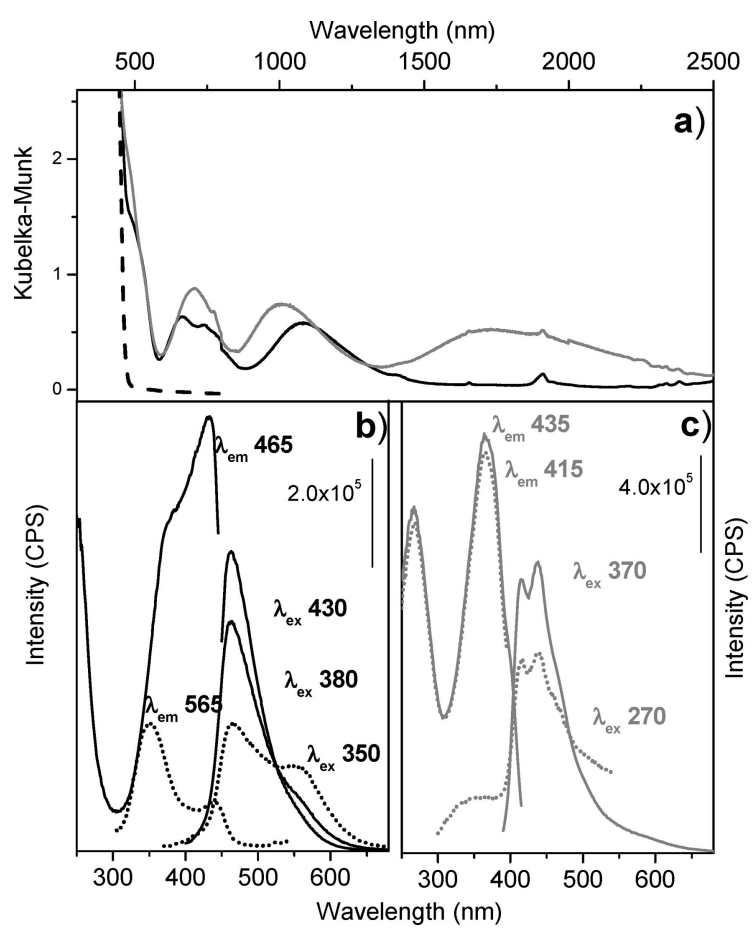

Figure 4. (a) UV-vis spectra of CPO-27-Ni and dhtp linker (solid and dashed lines, respectively). Black and gray curves are used for as synthesized and dehydrated samples, respectively. (b, c) Photoluminescence of as synthesized (black curves) and dehydrated (gray curves) CPO-27-Ni, respectively. Solid and dotted curves are used to identify corresponding excitation and emission spectra.

couples showing correlation parameters below 0.5 in absolute value. The adsorbed water molecule was located at $R_{\text {adsorbate }}=$ $2.10 \pm 0.04 \AA$, a value in perfect agreement with that obtained from powder XRD $(2.081 \AA)$. Much less can be said for the corresponding Debye-Waller factor, as the optimized $\sigma^{2}$ (adsorbate) value has the same magnitude as its associated error, as also testified by its high correlation with other parameters, vide supra. The presence of water strongly modifies all distances: $\left\langle\mathrm{R}_{\mathrm{O}}\right\rangle, R_{\mathrm{Ni1}}$, and $R_{\mathrm{Ni2}}$ increase by $0.04,0.09$, and 0.04 $\AA$, respectively. This picture is in fair agreement with the values obtained from powder XRD; see values reported in parentheses in Table 1.

3.2. Electronic Spectroscopies. 3.2.1. $D R-U V-V i s-$ NIR. CPO-27-Ni has a strong yellow-green color given by the combination of electronic transitions associated with the organic linker $\left(\mathrm{H}_{4} \mathrm{dhtp}\right)$ with those related to the presence of $\mathrm{Ni}(\mathrm{II})$ cations. Figure 4a) compares the UV-vis DR spectra of CPO-27-Ni sample as synthesized (hydrated; black curve) with that obtained after dehydration (gray curve). The spectrum of the hydrated sample is characterized by the presence of three main features: a band at $1100 \mathrm{~nm}$, a feature constituted by a double peak at 655 and $750 \mathrm{~nm}$ and a component at about $500 \mathrm{~nm}$. The last one is partially hidden by the intense absorption with an edge at $460 \mathrm{~nm}$, associated with the lowest $\pi-\pi^{*}$ energy transition due to the organic linker (dashed line). The other three main bands can be easily assigned by considering the UV-vis-NIR spectrum of a $\mathrm{Ni}(\mathrm{II})$ aqueous solution as model, where $\mathrm{Ni}(\mathrm{II})$ has an $\mathrm{O}_{h^{-}}$ like symmetry. In this case, the three components, observed at 1150, 690 and $425 \mathrm{~nm}$, are assigned to spin-allowed $\mathrm{d}-\mathrm{d}$ transitions: ${ }^{3} \mathrm{~A}_{2 \mathrm{~g}}\left({ }^{3} \mathrm{~F}\right) \rightarrow{ }^{3} \mathrm{~T}_{1 \mathrm{~g}}\left({ }^{3} \mathrm{P}\right),{ }^{3} \mathrm{~A}_{2 \mathrm{~g}}\left({ }^{3} \mathrm{~F}\right) \rightarrow{ }^{3} \mathrm{~T}_{1 \mathrm{~g}}\left({ }^{3} \mathrm{~F}\right)$, and ${ }^{3} \mathrm{~A}_{2 \mathrm{~g}}\left({ }^{3} \mathrm{~F}\right) \rightarrow{ }^{3} \mathrm{~T}_{2 \mathrm{~g}}\left({ }^{3} \mathrm{~F}\right)$, respectively. Similar features were observed in the case of $\mathrm{MgGa}_{2} \mathrm{O}_{4}$ or phosphate glasses doped with $\mathrm{Ni}(\mathrm{II}) .^{50,51}$

The thermal treatment in vacuo at $393 \mathrm{~K}$ produces deep changes in the optical spectrum: a blue shift for all the components, and above all, the appearance of a new band at $1780 \mathrm{~nm}$. This profile is extremely similar to what Ciampolini. ${ }^{52}$ observed in case of a five-coordinated $\mathrm{Ni}$ (II) species in a squared-pyramidal geometry; the assignment of the electronic transitions is as it follows: ${ }^{3} \mathrm{~B}_{1}\left({ }^{3} \mathrm{~F}\right) \rightarrow{ }^{3} \mathrm{E}(1)\left({ }^{3} \mathrm{~F}\right)$, ${ }^{3} \mathrm{~B}_{1}\left({ }^{3} \mathrm{~F}\right) \rightarrow{ }^{3} \mathrm{~A}_{2}\left({ }^{3} \mathrm{~F}\right),{ }^{3} \mathrm{~B}_{1}\left({ }^{3} \mathrm{~F}\right) \rightarrow{ }^{3} \mathrm{~B}_{2}\left({ }^{3} \mathrm{~F}\right),{ }^{3} \mathrm{~B}_{1}\left({ }^{3} \mathrm{~F}\right) \rightarrow{ }^{3} \mathrm{E}(2)\left({ }^{3} \mathrm{P}\right)$, ${ }^{3} \mathrm{~B}_{1}\left({ }^{3} \mathrm{~F}\right) \rightarrow{ }^{3} \mathrm{E}\left({ }^{3} \mathrm{P}\right),{ }^{3} \mathrm{~B}_{1}\left({ }^{3} \mathrm{~F}\right) \rightarrow{ }^{3} \mathrm{~A}_{2}\left({ }^{3} \mathrm{P}\right)$. This result indicates that the removal of water molecules directly coordinated to $\mathrm{Ni}$ (II) species causes a substantial modification of the electronic structure of the metal. The change in symmetry and ligand field causes a rearrangement of the metal states as reported above.

3.2.2. XANES. Similar symmetry changes are deduced from XANES spectra (Figure 2c). Upon water removal, several changes in the XANES spectra are observed, but no shift of the edge position occurs, testifying that the nickel oxidation state remains +2 . The main changes can be summarized as it follows: (i) a decrease in the white line intensity (first resonance after the edge, from 1.59 to 1.44) accompanied by a small blue shift (from 8350.6 to 8351.4 $\mathrm{eV})$; (ii) the appearance of a new electronic transition around $8339.7 \mathrm{eV}$ (0.22 in normalized intensity) (bottom inset in Figure 2c)); (iii) the increase in intensity (from 0.039 to 0.051 ) and a red shift (from 8333.3 to $8332.9 \mathrm{eV}$ ) of the very weak pre-edge feature (top inset in Figure 2c) due to $1 \mathrm{~s} \rightarrow 3 \mathrm{~d}$ electronic transition. The significant reduction of the white line intensity reflects the decrease of the average coordination of the absorbing atom. ${ }^{53-56}$ No $1 \mathrm{~s} \rightarrow 4 \mathrm{p}$ (bottom inset Figure 2c) electronic transitions are observed for the hydrated sample, probably because too close to the edge to be resolved. Water removal causes a symmetry change for $\mathrm{Ni}$ (II) from octahedral-like to square-pyramidal-like, implying the removal of the degeneration of p-levels (splitting between $\mathrm{p}_{z}$ and $\mathrm{p}_{x}, \mathrm{p}_{y}$, being $x y$ the pyramidal plane) and the loss of the inversion center. Consequently, a pre-edge component appears upon dehydration at $8339.7 \mathrm{eV}$, which is attributed to the $1 \mathrm{~s} \rightarrow 4 \mathrm{p}_{z}$ electronic transition. The splitting of the $1 \mathrm{~s}$ to $\mathrm{p}$ level transitions has already been observed in the XANES spectra for other metal centers when the $p$ degeneration was removed by symmetry reduction. ${ }^{57-60}$ Finally, the very weak pre-edge feature around $8333 \mathrm{eV}$

(50) Ravikumar, R.; Yamauchi, J.; Chandrasekhar, A.; Reddy, Y. P.; Rao, P. S. J. Mol. Struct. 2005, 740, 169-173.

(51) Suzuki, T.; Murugan, G. S.; Ohishi, Y. J. Lumin. 2005, 113, 265270.

(52) Ciampolini, M. Inorg. Chem. 1966, 5, 35-40.

(53) Berlier, G.; Spoto, G.; Bordiga, S.; Ricchiardi, G.; Fisicaro, P.; Zecchina, A.; Rossetti, I.; Selli, E.; Forni, L.; Giamello, E.; Lamberti, C. J. Catal. 2002, 208, 64-82.

(54) Bolis, V.; Bordiga, S.; Lamberti, C.; Zecchina, A.; Carati, A.; Rivetti, F.; Spano, G.; Petrini, G. Langmuir 1999, 15, 5753-5764.

(55) Bordiga, S.; Bonino, F.; Damin, A.; Lamberti, C. Phys. Chem. Chem. Phys. 2007, 9, 4854-4878.

(56) Groppo, E.; Prestipino, C.; Cesano, F.; Bonino, F.; Bordiga, S.; Lamberti, C.; Thüne, P. C.; Niemantsverdriet, J. W.; Zecchina, A. J. Catal. 2005, 230, 98-108.

(57) Prestipino, C.; Berlier, G.; Llabrés, i; Xamena, F. X.; Spoto, G.; Bordiga, S.; Zecchina, A.; Palomino, G. T.; Yamamoto, T.; Lamberti, C. Chem. Phys. Lett. 2002, 363, 389-396. 
increases in intensity upon dehydration because of loss of inversion center. This change of symmetry also accounts for the increase of the component due to $1 \mathrm{~s} \rightarrow 3 \mathrm{~d}$ electronic transition, which is forbidden in a perfect $O_{h}$ symmetry.

3.2.3. Photoluminescence. The combination of aromatic linkers (2,5-dihydroxyterephthalic acid) with transition metal ions suggests the possibility to observe also some relevant features associated to electronic emissions, as already shown in the case of other MOFs, ${ }^{10,61,62}$ where the metal coordination to luminescent organic ligands had been able to enhance or quench and shift luminescent emission of the pure organic ligands. Parts b) and c) of Figure 4 report photoluminescence results obtained on as synthesized (black curves) and dehydrated samples (gray curves), respectively. For both the samples, excitation and emission spectra, obtained by fixing the emission or the excitation wavelength respectively, are reported in the same graph. Fixed emission and excitation wavelengths are indicated for each spectrum. Different mark styles refer to the corresponding excitation-emission couple of spectra.

Hydrated sample (Figure 4b) is characterized by strong luminescence in the visible region. The most favorable excitation was found across the UV and visible regions $(350-450 \mathrm{~nm})$, where the lowest energy electronic transition associated to the linker and the strongest $\mathrm{d}-\mathrm{d}$ transition of $\mathrm{Ni}(\mathrm{II})$ cations are present (see section 3.2.1 and Figure 4a). In particular, excitations at 380 and $430 \mathrm{~nm}$ give rise to an intense emission peak at $465 \mathrm{~nm}$. An excitation at $350 \mathrm{~nm}$ causes a two peaks emission spectrum with maxima at 465 and $565 \mathrm{~nm}$. By comparing the photoluminescence of CPO27-Ni and $\mathrm{H}_{4} \mathrm{dhtp}$ linker (see the Supporting Information, Figure S2), it is observed that the linker is significantly more fluorescent than the MOF. The absence of a double emission peak for the linker excited at $350 \mathrm{~nm}$ implies that the emission peak observed for CPO-27-Ni at $565 \mathrm{~nm}$ can be assigned to a charge transfer from the ligand to the metal (LMCT). In the literature, many examples of emission spectra due to LMCTs and not aromatic ligands are reported. ${ }^{61,62}$

CPO-27-Ni luminescence is perturbed upon water removal and change of Ni(II) coordination sphere (see Figure 4c). In particular, upon dehydration (thermal treatment at $393 \mathrm{~K}$ ), emission spectra shift at lower wavelengths and are split (maxima at 415 and $435 \mathrm{~nm}$ ), because of degeneration removal by symmetry reduction. Excitation both at 270 and $370 \mathrm{~nm}$ cause the same type of emission.

3.3. Vibrational Spectroscopies: IR and Raman. Effect of dehydration on CPO-27-Ni has been investigated also by vibrational spectroscopies: both IR and Raman. Being the two techniques complementary, they permitted us to appreciate all the vibrational aspects of the phenomenon.

(58) Llabrés, i; Xamena, F. X.; Fisicaro, P.; Berlier, G.; Zecchina, A.; Palomino, G. T.; Prestipino, C.; Bordiga, S.; Giamello, E.; Lamberti, C. J. Phys. Chem. B 2003, 107, 7036-7044.

(59) Prestipino, C.; Solari, P. L.; Lamberti, C. J. Phys. Chem. B 2005, 109, 13132-13137.

(60) Prestipino, C.; Capello, L.; D’Acapito, F.; Lamberti, C. Phys. Chem. Chem. Phys. 2005, 7, 1743-1746.

(61) Huang, K. L.; Hu, C. W. Inorg. Chim. Acta 2007, 360, 3590-3596.

(62) Wang, L.; Yang, M.; Li, G. H.; Shi, Z.; Feng, S. H. Inorg. Chem. 2006, 45, 2474-2478.

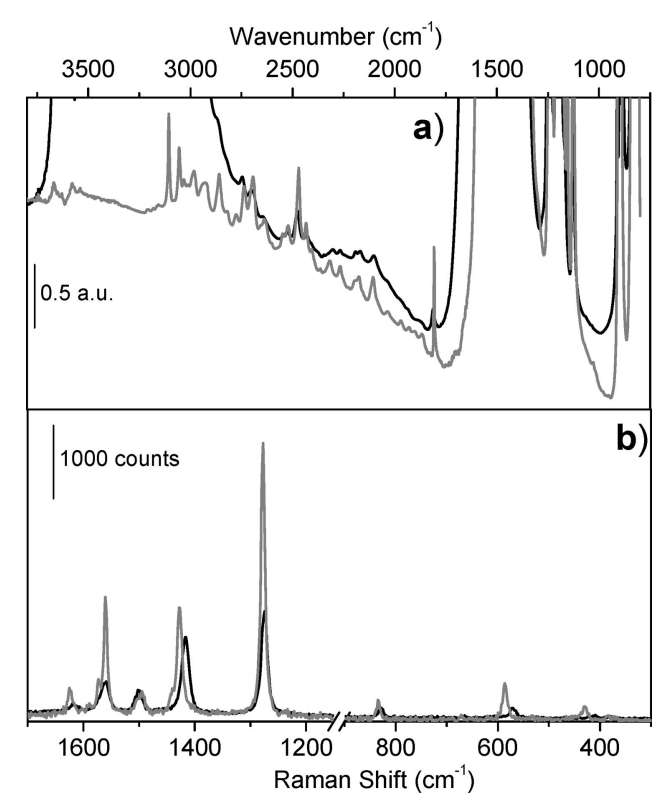

Figure 5. (a) IR and (b) Raman spectra of CPO-27-Ni in air and outgassed at $393 \mathrm{~K}$ : black and gray curves, respectively.

Starting from IR experiment (part a of Figure 5), the hydrated (in air) CPO-27-Ni (black curve) shows, in almost the whole range, quite intense, out of scale absorptions due to the presence of water. Upon outgassing at $393 \mathrm{~K}$, all water is desorbed (gray curve) and the spectrum becomes dominated by the bands due to the organic part of the MOF. In the range from ca. $3200 \mathrm{~cm}^{-1}$ to ca. $1650 \mathrm{~cm}^{-1}$, a huge number of bands mainly due to combinations and overtones are visible, whereas at lower frequency out of scale absorptions due to the organic part of the framework are present. Framework bands are too intense in the IR spectrum to allow a detailed assignment.

In this case, Raman spectroscopy is more suitable, as both water and MOF vibrations are weak Raman scatterers. Only at frequencies lower than $1650 \mathrm{~cm}^{-1}$ few Raman bands are well observable. Most of the features are due to the vibrational modes of the MOF linker. Starting with the sample in air, the bands at 1619,1560 , and $570 \mathrm{~cm}^{-1}$ can be ascribed to benzene ring vibrations, with the two at higher frequency being due to stretching modes and the lower one to a ring deformation mode. Features at 1501 and 1416 $\mathrm{cm}^{-1}$ can be respectively assigned to $v\left(\mathrm{COO}^{-}\right)_{\text {asym }}$ and $v\left(\mathrm{COO}^{-}\right)_{\text {sym. }}$. The intense band at $1275 \mathrm{~cm}^{-1}$ can be attributed to $v(\mathrm{C}-\mathrm{O})$ vibration due to the deprotonated species derived from the hydroxyl group. The minor feature at $827 \mathrm{~cm}^{-1}$ is ascribed to ring $\mathrm{C}-\mathrm{H}$ bending modes. ${ }^{10,48}$ Finally, the band at $410 \mathrm{~cm}^{-1}$ can be associated with a vibrational mode involving nickel, presumably a $v(\mathrm{Ni}-$ OLigand) one. ${ }^{63-65}$

Upon water removal at $393 \mathrm{~K}$, some relevant changes occur in the framework vibrational region in both the frequency and the relative intensities of the Raman bands.

(63) Wysokiñski, R.; Morzyk-Ociepa, B.; Glowiak, T.; Michalska, D. J. Mol. Struct. 2002, 606, 241-251.

(64) Campos-Vallette, M. M.; Figueroa, K. A.; Latorre, R.; Manriquez, V.; Costamagna, J.; Otero, M. Vib. Spectrosc. 1992, 4, 77-90.

(65) Odo, J.; Mifune, M.; Iwado, A.; Saito, Y.; Tanaka, Y.; Motohashi, N.; Machida, K. Chem. Pharm. Bull. 1991, 39, 247-250. 
As far as the frequency shifts are concerned, most of the components are sensibly red-shifted (the bands at 1625, 1561, $1427,1278,833,586$, and $430 \mathrm{~cm}^{-1}$ move respectively to $1618,1558,1415,1273,827,570$, and $410 \mathrm{~cm}^{-1}$ ). An exception is made for the band around $1500 \mathrm{~cm}^{-1}$, that remains almost unshifted. Coming to the band intensities, any direct comparison of the two spectra is not possible as the measures have not been performed on the same focused point. Assuming that the frequency invariance of the 1500 $\mathrm{cm}^{-1}$ band reflects a negligible perturbation of the corresponding vibrational mode upon water desorption, the spectra reported in Figure 5b have been normalized to this component. Under this assumption, most of the bands decrease in intensity upon $\mathrm{H}_{2} \mathrm{O}$ removal. This global decrease in intensity of all the spectrum features can be justified by considering that upon dehydration the framework undergoes a loose of local symmetry.

\section{Interaction with NO: Spectroscopic and Calorimetric Studies}

$\mathrm{NO}$ gas is a relevant signaling molecule in mammals, acting both as a poison that competes with oxygen in the breath cycle and as a beneficial agent able to lower the blood pressure. Moreover, it is a very important intermediate in the chemical industry. In the mean time, as NO is a dangerous toxic air pollutant (produced by automobile engines and power plants) and participates in ozone layer depletion, it must follow very strict emission legislation limits. For these reasons, a large effort is devoted in the field of NO traps and sensors for bio- and green chemistry applications. ${ }^{31,32}$ In the field of biomolecular systems, iron proteins are probably the most investigated. Nevertheless, an increasing effort has been devoted recently to finding alternative systems. ${ }^{66}$ In this area, MOFs seem to be very promising, as transition metal ions are one of the main components of the structure and very often offer a coordination site vacancy. ${ }^{32}$

4.1. Electronic Properties of the Nitrosyl Adducts: DR-UV-vis-NIR and XANES Spectroscopies. The interaction of NO with CPO-27-Ni causes an evident color change of the sample: from yellow to olive color. Figure 6 compares the DR-UV-vis-NIR spectra of the dehydrated CPO-27-Ni (gray curve) and of the sample in interaction with NO (black curve). The spectrum has been collected after contact with 10 mbar of $\mathrm{NO}$ and sample equilibration. The spectrum does not substantially change upon pumping at room temperature for $30 \mathrm{~min}$ under dynamic vacuo (spectrum not reported for the sake of clearness). The most relevant changes upon NO interaction consist in a red shift of the edge (that covers the highest energy $d-d$ transition) and the growth of an important absorption at about $650 \mathrm{~nm}$, assigned to a LMCT from NO to $\mathrm{Ni}(\mathrm{II})$. The frequency of this band is exceptionally low for a charge transfer and its intensity is too high for a $d-d$ transition. However, similar features have been already found in systems containing $\mathrm{Cr}(\mathrm{II})$ interacting with $\mathrm{NO}$ molecule $^{67}$ and with

(66) Ford, P. C.; Lorkovic, I. M. Chem. Rev. 2002, 102, 993-1017.

(67) Groppo, E.; Lamberti, C.; Bordiga, S.; Spoto, G.; Zecchina, A. Chem. Rev. 2005, 105, 115-183.

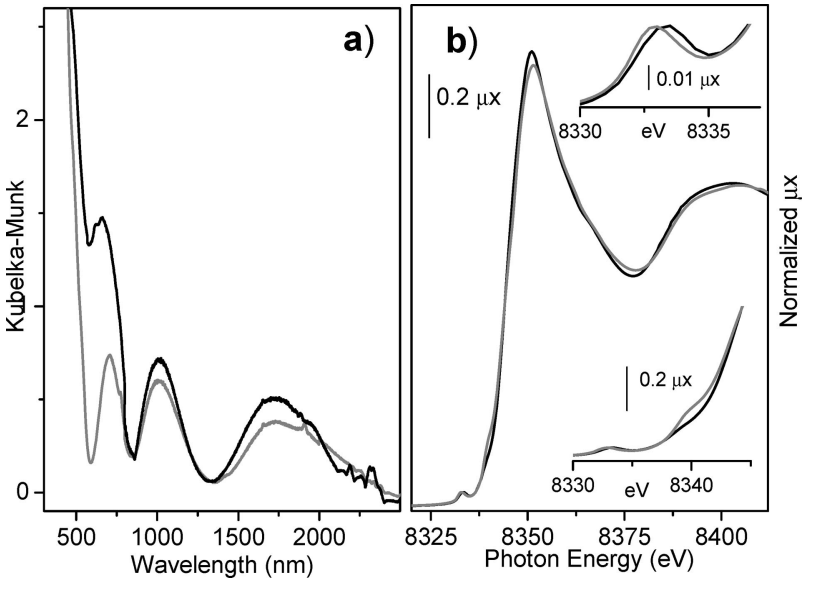

Figure 6. CPO-27-Ni in interaction with NO. (a) UV-vis-NIR spectra. (b) Normalized XANES. Insets report a zoom on the dipole forbidden $1 \mathrm{~s}$ $\rightarrow 3 \mathrm{~d}$ (top) and on the dipole allowed $1 \mathrm{~s} \rightarrow 4 \mathrm{p}$ (bottom) electronic transitions. Gray curves: dehydrated sample; black curves: after NO dosage.

inorganic complexes composed of ligands with a similar electronic structure, namely $\mathrm{CN}^{-}$and $\mathrm{O}_{2}{ }^{-}$, which differ from NO by one or two electrons, respectively. ${ }^{68}$ In both cases, low energy absorptions were observed and assigned to LMCT involving these electron rich ligands. The new band overshadows the $\mathrm{d}-\mathrm{d}$ component observed at $705 \mathrm{~nm}$ on the dehydrated sample. Finally, the $\mathrm{d}-\mathrm{d}$ transition observed at $1780 \mathrm{~nm}$ appears now at $1740 \mathrm{~nm}$, whereas the component at $1010 \mathrm{~nm}$ remains nearly unperturbed. These spectroscopic evidences suggest that $\mathrm{NO}$ is bonded to the $\mathrm{Ni}(\mathrm{II})$ sites, which, however, maintain a low local symmetry structure, as testified by the persistence of the band centered at $1740 \mathrm{~nm}$, which is absent in the hydrated sample.

This general picture is confirmed by XANES data obtained in a parallel experiment. NO coordination results in a small increase in the white line intensity, as expected when the average coordination of the absorbing atom increases (Figure 6b). Furthermore, $\mathrm{NO}$ adsorption causes an intensity decrease of the $1 \mathrm{~s} \rightarrow 4 \mathrm{p}_{z}$ electronic transition at $8339.7 \mathrm{eV}$, and perturbs the $\mathrm{d}$ orbitals of $\mathrm{Ni}(\mathrm{II})$ as monitored by the blue shift of the $1 \mathrm{~s} \rightarrow 3 \mathrm{~d}$ electronic transition from 8332.9 to $8333.5 \mathrm{eV}$.

The perturbation of the XANES and UV-vis spectra upon dosage of $\mathrm{NO}$ is less important than that observed upon hydration. This could suggests that $\mathrm{H}_{2} \mathrm{O}$ is a stronger ligand with respect to $\mathrm{NO}$ and that the overlapping of $\mathrm{Ni}$ (II) molecular orbitals with those of the adsorbing molecule is less extended in the case of NO. However, it is also important to consider that $\mathrm{H}_{2} \mathrm{O}$ molecules tend to give aggregates through the formation of strong $\mathrm{H}$-bonds, so amplifying the response of the structure. NO is a "selective" ligand toward $\mathrm{Ni}(\mathrm{II})$, whereas $\mathrm{H}_{2} \mathrm{O}$, besides interacting with $\mathrm{Ni}(\mathrm{II})$, completely fills the MOF channels.

4.2. Vibrational Properties of the Nitrosyl Adducts: IR and Raman Spectroscopies. It is generally ascertained that NO coordinates to transition metal centers through the nitrogen atom. The character of the NO ligand can range

(68) Ghiotti, G.; Garrone, G.; Della Gatta, G.; Fubini, B.; Giamello, E. J. Catal. 1983, 80, 249-262. 
from that of a nitrosyl cation $\left(\mathrm{NO}^{+}\right)$, which binds to the metal with a $\mathrm{M}-\mathrm{N}-\mathrm{O}$ angle close to $180^{\circ}$ (linear), to that of a nitrosyl anion $\left(\mathrm{NO}^{-}\right)$, for which a bond angle in the $120-140^{\circ}$ range (bent) might be generally anticipated. In the former case, considerable charge transfer to the metal occurs, while in the latter, charge transfer is in the opposite direction. The electron in the antibonding orbital of NO is donated to the metal atom forming a $\sigma$-bond, whereas a $\pi$-bond is then provided by the donation of the $d$ electrons from metal to the antibonding orbital of nitric oxide. Vibrational spectra reflect the nature of the binding between $\mathrm{NO}$ and the metal showing a red shift with respect to the vibration of the free molecule $\left(\tilde{v}_{0}(\mathrm{NO})=1876 \mathrm{~cm}^{-1}\right)$, that progressively increases with increasing the fraction of $\pi$-bonding. ${ }^{66,69}$ The situation becomes slightly more complex in the case of NO adsorbed on a surface. When NO is adsorbed on a well defined surface, difference is made between linear and tilted adsorption geometries (both characterized by a $\mathrm{Ni}-\mathrm{N}-\mathrm{O}$ angle close to $180^{\circ}$ ), depending whether the $\mathrm{Ni}-\mathrm{N}-\mathrm{O}$ direction is perpendicular or not to the surface. In case of (001) faces of microcrystalline NiO, it has been found that linear NO, formed at low coverages, is accompanied by tilted $\mathrm{NO}$ at medium/high coverages, which are characterized by a coverage dependent $\tilde{v}(\mathrm{NO})$ stretching frequency in the $1805-1799 \mathrm{~cm}^{-1}$ range due to both static and dynamic dipole-dipole interactions $\left(\Delta \tilde{\nu}_{\text {dyn }}\right.$ $=32 \mathrm{~cm}^{-1}$ and $\left.\Delta \tilde{\nu}_{\mathrm{st}}=-26 \mathrm{~cm}^{-1}\right){ }^{70-74}$ The Freund group in Berlin investigated with high resolution EELS the adsorption of $\mathrm{NO}$ on thin $\mathrm{NiO}(001)$ layers deposited on $\mathrm{Ni}(001)$ and on vacuum cleaved $\mathrm{NiO}(001)$ single crystal surfaces, ${ }^{72}$ finding a $\tilde{v}_{0}(\mathrm{NO})$ of $1800 \mathrm{~cm}^{-1}$.

The effect of NO interaction at room temperature on the vibrational properties of CPO-27-Ni is reported in Figure 7, where the Raman spectra of the dehydrated sample (gray curve) and after NO adsorption $\left(p_{\mathrm{e}}=0.005\right.$ mbar, black curve) are compared. The spectrum has been collected after admission of 5 mbar of NO, sample equilibration and removal of the reversible phase upon pumping at room temperature. As in the case of dehydration, the most significant changes in the framework vibrational modes are essentially related to the organic ligand. As already discussed above (see section 3.3 and Figure 5b) the spectra have been normalized to the band around $1500 \mathrm{~cm}^{-1}$. Adsorption of NO results in spectra modifications similar to those observed upon $\mathrm{H}_{2} \mathrm{O}$ coordination: most of the bands decrease in intensity and are shifted toward lower $\tilde{v}$. In particular, upon NO interaction, (i) the most affected bands are those at 1560 and $1426 \mathrm{~cm}^{-1}$, which lose about one order of magnitude

(69) Meiners, J. H.; Rix, C. J.; Clardy, J. C.; Verkade, J. G. Inorg. Chem. 1975, 14, 705-710.

(70) Escalona Platero, E.; Fubini, B.; Zecchina, A. Surf. Sci. 1987, 179, 404-424.

(71) Garrone, E.; Fubini, B.; Escalona Platero, E.; Zecchina, A. Langmuir 1989, 5, 240-245.

(72) Kuhlenbeck, H.; Odörfer, G.; Illing, G.; Menges, M.; Mull, T.; Freund, H.-J.; Pöhlchen, M.; Staemmler, V.; Witzel, S.; Scharfschwerdt, C.; Wennemann, K.; Liedtke, T.; Neumann, M. Phys. Rev. B 1991, 43, 1969-1989.

(73) Zecchina, A.; Scarano, D.; Bordiga, S.; Spoto, G.; Lamberti, C. Adv. Catal. 2001, 46, 265-397.

(74) Chiesa, M.; Paganini, M. C.; Giamello, E.; Di Valentin, C.; Pacchioni, G. J. Mol. Catal. A: Chem. 2003, 204-205, 779-786.

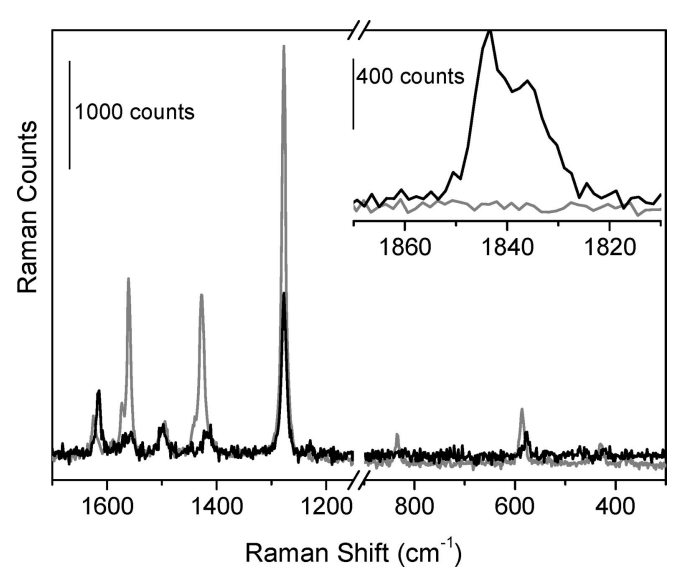

Figure 7. Raman spectra of CPO-27-Ni in interaction with NO: dehydrated sample (gray curve) and after NO dosage ( $p_{\mathrm{e}}=0.005 \mathrm{mbar}$ ) (black curve). The inset reports the typical $v(\mathrm{NO})$ region.

in intensity and are slightly red-shifted (at 1555 and 1417 $\mathrm{cm}^{-1}$ respectively); (ii) the components at 1275 and 585 $\mathrm{cm}^{-1}$ lose almost $50 \%$ of their intensity, the former does not shift, whereas the latter shifts at $578 \mathrm{~cm}^{-1}$; (iii) the very weak bands at 833 and $430 \mathrm{~cm}^{-1}$ fail below the signal-tonoise ratio. Finally, the band at $1625 \mathrm{~cm}^{-1}$ makes exception, doubling its intensity, while it undergoes a red-shift to 1615 $\mathrm{cm}^{-1}$.

The presence of adsorbed NO is testified by a complex band with maximum at $1843 \mathrm{~cm}^{-1}$, tailed in the low energy side, due to $\mathrm{Ni}(\mathrm{II}) \cdots \mathrm{NO}$ adducts formed upon $\mathrm{NO}$ dosages, see inset of Figure 7. The observation by Raman spectroscopy of absorptions due to the formation of surface species upon interaction with a gas phase is remarkable, as often the heat produced by the laser causes adduct desorption. This explains why the availability of surface adducts observed by Raman, is very rare and only few examples are found in the literature. ${ }^{75}$ The relative high frequency of this band suggests weak $\pi$-back-donation from Ni to NO molecules, thus favoring an almost linear adsorption geometry. Note that in case of CPO-27-Ni, the $\mathrm{Ni}$ (II) species arrangement consists in chains (see Figure 1b) and is consequently something intermediate between a surface and an isolated adsorption site.

Figure 8 reports the series of IR spectra collected at room temperature in adsorption (bottom part), in desorption (medium part) and upon successive contact with $\mathrm{H}_{2} \mathrm{O}$ vapor pressure (top part). Bold gray curve reported at the bottom part of the figure refers to the dehydrated sample in the form of a thin deposition on a silicon wafer. This choice is dictated by the need of strongly reduce the sample thickness with respect to a standard pellet, because of the high extinction coefficient of $v(\mathrm{NO})$ band that easily saturates, thus avoiding to appreciate the effect of pressure changes. The effect of NO interaction on a standard self-supporting pellet is reported in Figure S3 for sake of completeness. The first series of bands (bottom) have been obtained at different NO coverages. Due to the strong affinity of the Ni(II) site toward NO, successive NO dosages of 0.1 mbar gave equilibrium

(75) Damin, A.; Bonino, F.; Bordiga, S.; Groppo, E.; Lamberti, C.; Zecchina, A. ChemPhysChem. 2006, 7, 342-344. 


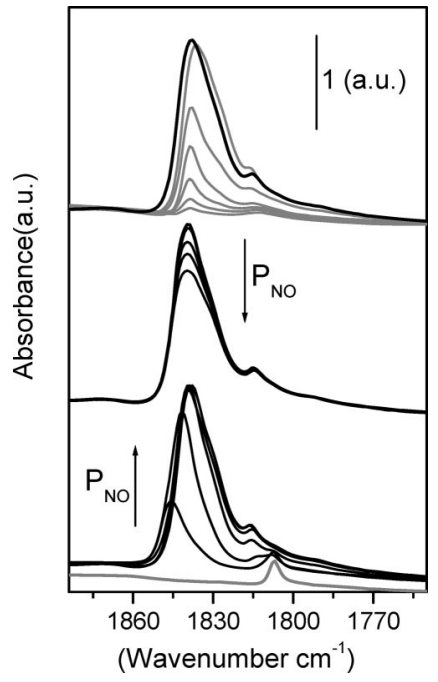

Figure 8. Bottom: FTIR spectra of increasing NO equilibrium pressures $\left(P_{\mathrm{NO}}\right)$ dosed at RT on CPO-27-Ni (equilibrium $p_{\max }=0.1 \mathrm{mbar}$ ). Bold gray curve, vertically translated for clarity, reports the spectrum collected before NO dosage, showing the framework mode at $1807 \mathrm{~cm}^{-1}$. Middle: spectra obtained upon successive progressive outgassing. Top: Effect of water dosage on the irreversible NO (last spectrum of the middle part). Black curve reports the effect of $0.1 \mathrm{mbar}_{2} \mathrm{O}$ dosage. Gray curves further interaction of water, at the vapor pressure as a function of increasing contact times (up to $10 \mathrm{~min}$ ).

pressure below 0.01 mbar. The final curve corresponds to an equilibrium $p_{\max }=0.1$ mbar. At the lowest $\mathrm{NO}$ coverages, a band at $1845 \mathrm{~cm}^{-1}$, clearly tailed at lower frequencies, is present. This feature is assigned to the $v(\mathrm{NO})$ of $\mathrm{Ni}(\mathrm{II}) \cdots \mathrm{NO}$ adducts. The red shift of the adsorbed NO with respect to free gaseous molecule $\left(\tilde{v}_{0}=1876 \mathrm{~cm}^{-1}\right)$ indicates a strong interaction involving some back-donation effect from the metal to the nitrosyl species. ${ }^{76}$ By increasing the coverage, a red shift up to $1838 \mathrm{~cm}^{-1}$ is observed, probably because of the filling of vicinal $\mathrm{Ni}$ (II) sites. The effect becomes even more strong at higher coverages where a condensed phase is formed (see Figure S3 in the Supporting Information). As already observed by Raman spectroscopy, NO adsorption induces some changes in the vibrational modes of the framework. In this case the band at $1807 \mathrm{~cm}^{-1}$ blue shifts progressively to $1816 \mathrm{~cm}^{-1}$ because of some combination mode of CPO-27-Ni. Desorption spectra (middle part of Figure 8 ) confirm that $\mathrm{NO}$ interacts very strongly with $\mathrm{Ni}(\mathrm{II})$ and the interaction is not completely reversible at room temperature upon outgassing in dynamic vacuo.

To investigate the possible application of this material for progressive NO release in biological media, the ability of water to displace the NO ligand has to be investigated. This has been done by dosing progressive amounts of water on a NO precontacted and evacuated sample and by monitoring the spectra time evolution (top part of Figure 8). At very low $\mathrm{H}_{2} \mathrm{O}$ dosages, no relevant changes are observed but an increase in the NO band intensity (black curve in the top part of Figure 8), because of the growth of the pressure inside the cell. Then, by dosing the water vapor pressure, $\mathrm{H}_{2} \mathrm{O}$ penetrates inside the pores, modifying the local dielectric constant as monitored by the small red shift undergone by

(76) Mihaylov, M.; Hadjiivanov, K. Langmuir 2002, 18, 4376-4383. the $\mathrm{N}-\mathrm{O}$ band (now at $1835 \mathrm{~cm}^{-1}$ ). Successively, upon increasing water contact time the gradual removal of $\mathrm{NO}$ is clearly visible (gray curves in the top part of Figure 8). No oxidation products have been observed. This behavior is optimal for a slow NO release inside a biological medium.

4.3. Structural Properties of the Ni(II) $\cdots$ NO Adducts: EXAFS Spectroscopy. EXAFS spectroscopy has been used to determine the structural properties of the $\mathrm{Ni}(\mathrm{II}) \cdots \mathrm{NO}$ adduct and the structural modification of the CPO-27-Ni framework upon NO adsorption. As already done previously (see section 3.1), the structure of the dehydrated $\mathrm{MOF}^{19}$ was used as starting model for the refinement. Two clusters were then constructed, by adding to the framework atoms a $\mathrm{NO}$ molecule (starting value for the $\mathrm{Ni}-\mathrm{N}$ distance $1.80 \AA$, and fixing $\mathrm{N}-\mathrm{O}$ at $1.20 \AA$ ) either linearly absorbed on the central $\mathrm{Ni}$ atom or with a bent geometry, fixing the $\mathrm{Ni}-\mathrm{N}-\mathrm{O}$ angle to $130^{\circ}$. In the case of EXAFS data analysis, the presence of tilted NO has not been considered as this geometry could have influence only on the MS paths involving both the NO molecule and light elements of the framework, whose contributions are too weak to compete with the strong $\mathrm{Ni}-\mathrm{Ni}$ ones.

To limit the number of fitting parameters, and the associated correlation problems, we applied the same procedure adopted for fitting the hydrated sample (vide supra section 3.1.2.) here. So the amplitude factor $S_{0}{ }^{2}$ and all framework Debye-Waller factors $\sigma^{2}(\mathrm{O}), \sigma^{2}(\mathrm{Ni} 1), \sigma^{2}(\mathrm{Ni} 2)$, and $\sigma^{2}$ were fixed to the values optimized in the fit of the dehydrated sample measured at RT (see Table 1). Additional parameters are the $\mathrm{Ni}-\mathrm{N}$ distance $\left(R_{\text {adsorbate }}\right)$ and corresponding Debye-Waller factor $\left(\sigma^{2}\right.$ (adsorbate) $)$; the distance of the $\mathrm{SS} \mathrm{Ni}-\mathrm{O}_{\mathrm{NO}}$; and the triangular (linear) MS path involving the NO molecule, which has been fixed by geometrical constraints to be functions of $R_{\text {adsorbate }}$. According to both IR (showing only mononitrosyl adducts) and microcalorimetry (volumetric data showing the formation of $95 \%$ of $1: 1$ complexes, see below), the stoichiometry $\mathrm{Ni}(\mathrm{II}) \cdots \mathrm{NO}$ was assumed, allowing us to fix the amplitude factor of the signal associated to the NO molecule. Under those assumptions, a seven-parameter fit was run.

The results of the two fits are summarized in Table 1, whereas Figure 9 reports, for the linear model, the comparison between experimental and theoretical curves in $k$ - (a) and $R$-space (b). Both fits agree in the location of the NO molecule: $\mathrm{Ni}-\mathrm{N}$ distance being optimized at $1.85 \pm 0.02$ and $1.87 \pm 0.02 \AA$, in the linear and bent models, respectively. This insertion causes an almost negligible modification of the average $\mathrm{Ni}-\mathrm{O}$ first shell distance that does not undergo the stretching observed when water was coordinated. The Ni-NO distance is determined with good precision in the $1.85-1.87 \AA$ range because of the strong intensity of the $\mathrm{Ni}-\mathrm{N}$ path (the most intense among all) and because of a significant difference in distance from the framework oxygen contributions, located at higher $R$ values. Usually EXAFS is able to discriminate between linear or bent adsorption of a diatomic molecule on a metal center, because of the focusing effect that enhances the MS contributions in case of linear alignment of scattering 


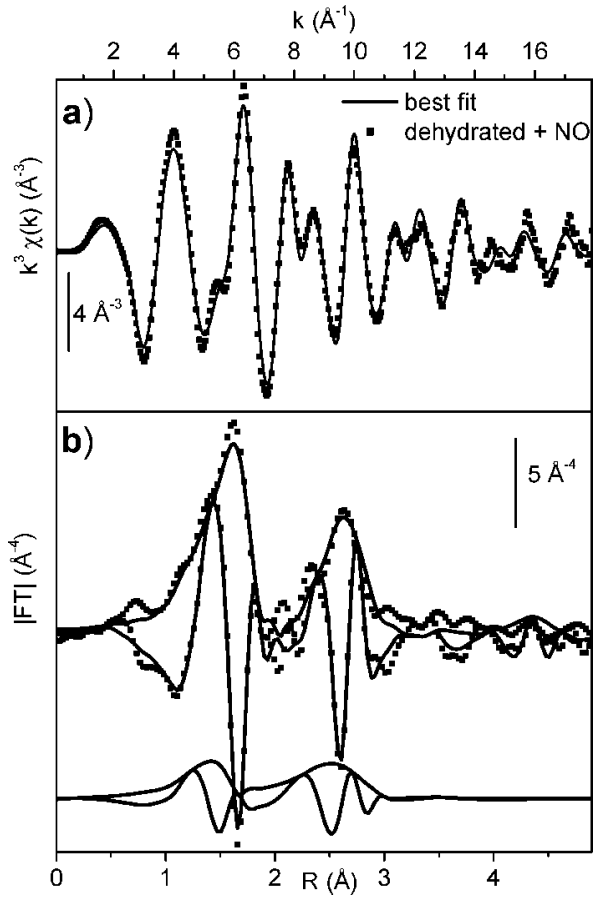

Figure 9. X-ray absorption data collected at RT on dehydrated CPO-27-Ni after interaction with NO. (a): $\mathrm{k}^{3}$-weighted $\chi(\mathrm{k})$, scattered squares, compared with the best fit (full line). Part (b): corresponding FT in their modulus and imaginary part. Vertically translated is the contribution of the NO molecule optimized in the fits using the linear cluster (both modulus and imaginary parts are reported).

atoms. ${ }^{60,77,78}$ Unfortunately, in this case, EXAFS is not able to unambiguously discriminate between the two molecular orientations. This is due to the fact that the contribution of the $\mathrm{O}$ atom of the $\mathrm{NO}$ molecule falls around $3 \AA$, i.e., in the region dominated by the strong $\mathrm{Ni}-\mathrm{Ni}$ contribution at 2.9 $\AA$, see Figure $9 \mathrm{~b}$. The analysis performed using the linear model resulted in a slightly better numerical fit: $R$-factor $=$ 0.045 (see Table 1) with respect to 0.052 . This difference (about 15\%) is not huge but the numbers can be directly compared as the two fits run on exactly the same fitting parameters. We can also conclude that EXAFS slightly favors a $\mathrm{Ni}-\mathrm{N}-\mathrm{O}$ angle closer to $180^{\circ}$ than to $130^{\circ}$. Note that a good fit (R-factor $=0.043$ ) was obtained also with a cluster having $\mathrm{Ni}-\mathrm{N}-\mathrm{O}$ angle $=160^{\circ}$ (not reported for brevity).

4.4. Calorimetry. In Figure 10, the primary and secondary volumetric isotherms for the $\mathrm{NO}$ adsorption on CPO-27-Ni as function of the equilibrium pressure $P_{\mathrm{e}}$ are reported. In the inset of Figure 10 the corresponding calorimetric isotherms are also reported (integral heat $Q_{\text {int }}$ as function of $P_{\mathrm{e}}$ ). The differential heat of adsorption $q_{\text {diff }}$ (defined as $\Delta Q_{\text {int }} /$ $\left.\Delta n_{\mathrm{a}}\right)$ as function of the coverage is reported in Figure 11. The adsorbed NO amounts $n_{\mathrm{a}}$ have been normalized to the moles of $\mathrm{Ni}$ atoms present in the activated $\mathrm{CPO}-27-\mathrm{Ni}$ material supposed stoichiometric and with all the $\mathrm{Ni}$ atoms available to the interaction (empirical formula of CPO-27$\mathrm{Ni}: \mathrm{C}_{4} \mathrm{HO}_{3} \mathrm{Ni}, 155.7401 \mathrm{~g} / \mathrm{mol}$ ) in order to make easier the comparison with the spectroscopic data. For each NO dose

(77) Westre, T. E.; Dicicco, A.; Filipponi, A.; Natoli, C. R.; Hedman, B.; Solomon, E. I.; Hodgson, K. O. J. Am. Chem. Soc. 1994, 116, 67576768.

(78) Lamberti, C.; Palomino, G. T.; Bordiga, S.; Berlier, G.; D'Acapito, F.; Zecchina, A. Angew. Chem., Int. Ed. 2000, 39, 2138-2141.

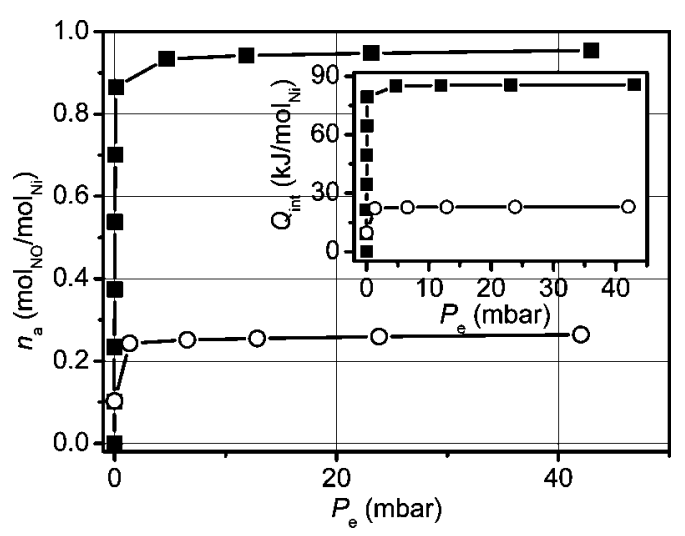

Figure 10. Plot of the primary (solid symbols) and secondary (open symbols) excess volumetric isotherms obtained for $\mathrm{NO}$ adsorption on CPO-27-Ni at $303 \mathrm{~K}$ as a function of the equilibrium pressure $P_{\mathrm{e}}$. The molar NO amounts $n_{\mathrm{a}}$ have been normalized to the moles of $\mathrm{Ni}$ atoms present in the MOF sample, supposing all the $\mathrm{Ni}$ atoms available to the interaction with NO. In the inset, the corresponding calorimetric isotherms are also shown.

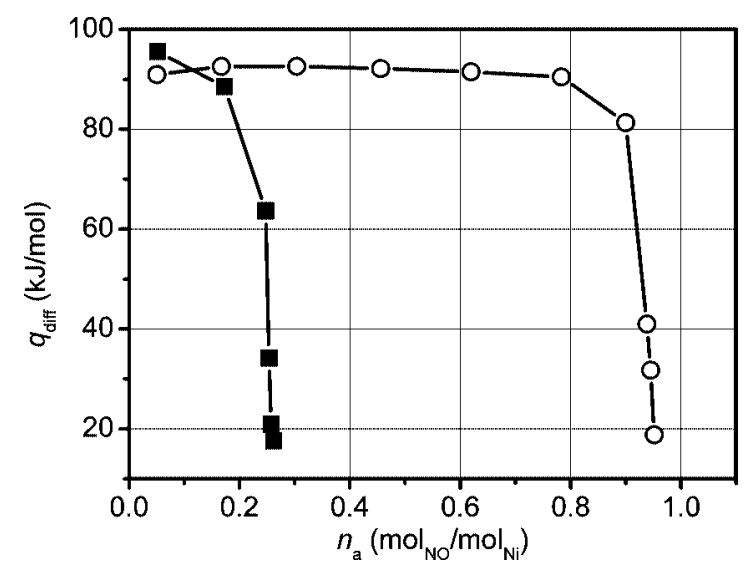

Figure 11. Dependence of the differential molar adsorption heat $q_{\text {diff }}$ on coverage for $\mathrm{NO}$ adsorption on $\mathrm{CPO}-27-\mathrm{Ni}$ at $303 \mathrm{~K}$ (filled circles, first adsorption run; open circles, second adsorption run). The molar NO amounts $n_{\mathrm{a}}$ have been normalized to the moles of $\mathrm{Ni}$ atoms present in the CPO-27$\mathrm{Ni}$ sample, supposing all the $\mathrm{Ni}$ atoms available to the interaction with $\mathrm{NO}$.

admitted on the sample, thermokinetic data have also been recorded. The evolution with time of the calorimetric peak was in all cases typical of an instantaneous, nonactivated, molecular adsorption process. In fact, the thermogram recorded during the adsorption step of each single dose returned to the initial baseline in a time of ca. $45 \mathrm{~min}$, i.e., within the time response of the heat-flow calorimeter. ${ }^{36,54,79}$

Both the primary and the secondary isotherms show a type I behavior in which the saturation is reached at low pressures followed by a pseudoplateau at higher pressure of $\mathrm{NO}$ with a maximum uptake of 15.5 mass $\%(6.1 \mathrm{mmol} / \mathrm{g})$ corresponding to the formation of $95 \%$ of $1: 1$ complexes. The observed sharp uptake of $\mathrm{NO}$ at lower pressure indicates favorable sorption interactions between the CPO-27-Ni framework and NO molecules. Comparison with data obtained previously on HKUST- ${ }^{32}(3 \mathrm{mmol} / \mathrm{g})$ shows the potentiality of this material for NO storage.

The reversible NO fraction obtained from the secondary isotherm is of about $1 / 3$ of the overall uptake. The compari-

(79) Bolis, V.; Barbaglia, A.; Bordiga, S.; Lamberti, C.; Zecchina, A. J. Phys. Chem. B 2004, 108, 9970-9983. 
son between the adsorbed amounts in the first and in the second run evidence that the interaction of NO with the CPO$27-\mathrm{Ni}$ surface is largely irreversible upon evacuation $(72 \%$ at $P_{\mathrm{e}}=42 \mathrm{mbar}$ ) and that, at equilibrium pressures higher than 7 mbar, the adsorption of NO generates only species characterized by a lower adsorption heat and easily desorbed upon degassing. For what concerns the species formed at pressure lower than 1 mbar $(\mathrm{NO} / \mathrm{Ni} \leq 0.86)$, an almost constant differential adsorption heat is observed as expected on qualitative speculations. The $q_{\text {diff }}$ obtained in this first part of the isotherm $(90-92 \mathrm{~kJ} / \mathrm{mol})$ matches perfectly with the microcalorimetric study of $\mathrm{NO}$ adsorbed on microcrystalline $\mathrm{NiO}(001)$ by Escalona Platero et al. ${ }^{70}$ The quoted work reports a constant molar heat of adsorption of $81 \mathrm{~kJ} \mathrm{~mol}^{-1}$ in the $0<\theta<0.2$ coverage range, whereas at higher coverages, adsorbate-adsorbate interactions progressively reduce the molar heat of adsorption down to $69 \mathrm{~kJ} \mathrm{~mol}^{-1}$. This latter value is on the same order of magnitude of that found by Wichtendahl et al. ${ }^{80}$ for $\mathrm{NO}$ adsorption on a vacuum-cleaved single-crystal $\mathrm{NiO}(100)$ surface $(54.9 \mathrm{~kJ} /$ mol) using thermal desorption spectroscopy (TDS).

The $86 \%$ of the theoretical number of nickel atoms are then actually available to interact with NO, see Figure 11. This can be due to a not perfect evacuation of all the $\mathrm{H}_{2} \mathrm{O}$ molecules or to the fact that the material is not perfectly crystalline. The quite good resistance to aging in air of CPO$27-\mathrm{Ni}$ has been demonstrated in a previous work. ${ }^{28}$ This first part of the isotherm can be related to the formation of the $1: 1 \mathrm{Ni} \cdots \mathrm{NO}$ complexes, confirming what observed in FTIR and Raman studies, where these species were found to be strongly adsorbed and partially irreversible at room temperature (see Figure S3 in the Supporting Information). A complete desorption of NO can be obtained with an outgassing at $400 \mathrm{~K}$ in dynamic vacuo.

\section{Conclusions}

Structural modifications occurred upon dehydration of CPO-27-Ni give rise to substantial changes in all the spectroscopic features of this material and make it suitable to strongly bound simple molecules such as NO. A mild thermal treatment in vacuo at $393 \mathrm{~K}$ is sufficient to remove completely all the water present in the cavities keeping its high crystallinity and low concentration of defects. Structural data coming from EXAFS measurements of both as prepared and dehydrated sample are in very good agreement with those obtained by powder X-Ray diffraction, if the average values for $\mathrm{Ni}-\mathrm{O}$ distances are considered. Even if the framework symmetry does not change (the crystal structure remains in space group $R \overline{3}),{ }^{19}$ water removal produces deep modifications in the optical spectra: a blue shift for all the components

(80) Wichtendahl, R.; Rodriguez-Rodrigo, M.; Hartel, U.; Kuhlenbeck, H.; Freund, H. J. Surf. Sci. 1999, 423, 90-98. and the appearance of a new band at $1780 \mathrm{~nm}$, indicating the transformation of an octahedral six-coordinated $\mathrm{Ni}$ (II) into a five-coordinated $\mathrm{Ni}$ (II) species in a square-pyramidal geometry. Raman modes result sensible to the degree of hydration and in the dehydrated sample the intensity ratio among all the components changes. This behavior confirms that the whole framework of CPO-27-Ni "breathes" when water is removed. The coordination vacancy generated upon water elimination seems to be a very favorable site for NO adsorption as testified by all the results obtained from all the spectroscopic data. The formation of strongly bonded $\mathrm{Ni}$ (II) mononitrosyls has been documented by the appearance of new features in the optical spectra. In the DR-UV-vis-NIR spectrum, the most evident effect is the new strong band at about $650 \mathrm{~nm}$, assigned to a LMCT from NO to Ni(II), whereas the XANES profile shows a small increase in white line intensity, an intensity decrease in the $1 \mathrm{~s} \rightarrow 4 \mathrm{p}_{z}$ electronic transition at $8339.7 \mathrm{eV}$, and a blue shift of the $1 \mathrm{~s} \rightarrow 3 \mathrm{~d}$ electronic transition from 8332.9 to $8333.5 \mathrm{eV}$. Vibrational data exclude the formation of $\mathrm{Ni}(\mathrm{II}) \cdots \mathrm{NO}$ bent adducts. In both IR and Raman, the appearance of a very strong and resistant band at $1847 \mathrm{~cm}^{-1}$ indicates the formation of linear/ tilted Ni(II) $\cdots$ NO species. EXAFS shows that NO becomes the closer Ni ligand, located at 1.85-1.87 $\AA$ from the metal. The evolution with time of the calorimetric peak is typical of an instantaneous, nonactivated, molecular adsorption process. Both the primary and the secondary isotherms show a type I behavior in which the saturation is followed by a pseudoplateau at higher pressure of NO with a maximum uptake of $15.5 \mathrm{mass} \%(6.1 \mathrm{mmol} / \mathrm{g})$ corresponding to the formation of $95 \%$ of 1:1 complexes. The observed sharp uptake of $\mathrm{NO}$ at lower pressure indicates favorable sorption interactions between the CPO-27-Ni framework and NO molecules. Comparison with data obtained previously on HKUST $-1^{32}$ ( $3 \mathrm{mmol} / \mathrm{g}$ ) show the potentiality of this material for NO storage. The ability of $\mathrm{H}_{2} \mathrm{O}$ molecules to slowly displace $\mathrm{NO}$ from the $\mathrm{Ni}$ (II) sites makes this material a promising candidate for NO delivery inside biological tissues.

Acknowledgment. Adriano Zecchina and Laura Regli are kindly acknowledged for fruitful discussion. L. R. is also acknowledged for having contributed to the data. The authors are indebted to Russell Morris for giving them access to unpublished results on CPO-27-Ni. ${ }^{33}$ The authors thank Compagnia di San Paolo for financial support. This work is a part of the STREP project MOFCAT Contract number: NMP4CT-2006-033335.

Supporting Information Available: Electrostatic potential surface of CPO-27-Ni; Luminescence spectra of CPO-27-Ni in comparison with the luminescence spectrum of the pure ligand; infrared isotherm of adsorption and desorption of NO on CPO-27Ni.This material is available free of charge via the Internet at http://pubs.acs.org.

CM800686K 